\title{
Rapid Dendritic Remodeling in the Developing Retina: Dependence on Neurotransmission and Reciprocal Regulation by Rac and Rho
}

\author{
Wai T. Wong, Beverly E. Faulkner-Jones, Joshua R. Sanes, and Rachel O. L. Wong \\ Department of Anatomy and Neurobiology, Washington University School of Medicine, St. Louis, Missouri 63110
}

\begin{abstract}
We demonstrate that within the intact and spontaneously active retina, dendritic processes of ganglion cells exhibit rapid and extensive movements during the period of synaptogenesis. Marked restructuring occurs in seconds, but structural changes are relatively balanced across the dendritic arbor, maintaining overall arbor size and complexity over hours. Dendritic motility is regulated by spontaneous glutamatergic transmission. Both the rate and extent of the movements are decreased by antagonists to NMDA and non-NMDA glutamate receptors but are unaffected by tetrodotoxin, a sodium channel blocker. The
\end{abstract}

dendritic movements are actin dependent and are controlled by the Rho family of small GTPases. Transfection of dominantnegative and constitutively active mutants into ganglion cells showed that Rac and Rho exert reciprocal effects on motility. We suggest that the Rho family of small GTPases could integrate activity-dependent and -independent signals from afferents, thereby adjusting target motility and maximizing the chance for initial contact and subsequent synaptogenesis.

Key words: dendritic development; process motility; synaptogenesis; Rho; Rac; spontaneous activity; retinal ganglion cells
During embryogenesis, axons grow, often over long distances, to reach their targets, after which their growth cones form synapses. In this classic picture of synaptogenesis, derived primarily from static images and studies in vitro, the axon is viewed as the active partner, and the dendrite is viewed as its passive target. Indeed, axonal growth cones are elaborate sensorimotor structures that sense and integrate cues in their environment, extend filopodia, form intercellular attachments, and actively remodel as synapses form and mature (for review, see Mueller, 1999). However, not only extending axons but also developing dendrites bear filopodia (Vaughn et al., 1974; Berry and Bradley, 1976; Vaughn, 1989). Moreover, S. J. Smith and colleagues have directly visualized dendritic filopodia extending toward and initiating contact with ingrowing afferents in hippocampal cell cultures in vitro (Cooper and Smith, 1992; Dailey and Smith, 1996; Ziv and Smith, 1996) and in zebrafish embryos in vivo (Jontes et al., 2000). These observations raise the possibility that dendrites are more active participants in synaptogenic interactions than imagined previously. We therefore undertook studies aimed at obtaining a more complete view of how dendrites move, particularly during the period of synaptogenesis, in active circuits.

We chose to examine dendritic remodeling in the developing vertebrate retina. The retina is a suitable preparation for this study because it can be isolated as an intact sheet of tissue without disrupting its structure or function. In particular, we focused on the output neurons of the retina, the ganglion cells, in embryonic

\footnotetext{
Received Jan. 27, 2000; revised April 4, 2000; accepted April 11, 2000.

This work was supported by grants from the Human Frontiers Science Program and the McDonnell Foundation (R.O.L.W.), a grant from the National Health and Medical Research Council (Australia) (B.E.F.-J.), a grant from the National Institutes of Health (NIH) (J.R.S.), and an instrumentation grant from NIH. We are grateful to Dr. A. Hall for providing GTPase cDNA constructs, Drs. J. W. Lichtman, S. Eglen, W.-B. Gan, B. Nadarajah, K. Myhr, and C. Lohman for their critical reading of this manuscript, $\mathrm{R}$. Stacy for her help in data analysis, and Drs. J. Beiser and M. Gordon for help in statistical analysis.

Correspondence should be addressed to Dr. Rachel O. L Wong, Department of Anatomy and Neurobiology, Washington University School of Medicine, 660 South Euclid, St. Louis, MO 63110. E-mail:wongr@thalamus.wustl.edu.

Copyright (C) 2000 Society for Neuroscience 0270-6474/00/205024-13\$15.00/0
}

chick retina at the time that synapses are formed onto ganglion cell dendrites. By labeling developing ganglion cells with green fluorescent protein (GFP), we were able to follow dendritic remodeling within an intact circuit and to characterize its dynamic nature. We also assessed the role of intercellular communication in regulating dendritic remodeling. Specifically, we examined the role of endogenous glutamatergic neurotransmission during the time that glutamatergic synapses are formed onto ganglion cell dendrites. Our results indicated that dendritic remodeling in the developing retina is prominent and rapid, with terminal processes moving at rates of up to $10 \mu \mathrm{m} / \mathrm{min}$. These rapid movements are regulated by afferent neurotransmission; blockade of glutamatergic transmission suppresses dendritic motility and decreases the total dendritic length and the number of branch points in the dendritic tree. This indicated that glutamatergic signaling occurring in developing retinal circuits is important in increasing the rate of dendritic remodeling and maintaining the dendritic structure of the arbor.

We were also interested in the intracellular mechanisms that underlie rapid remodeling. Because terminal dendritic processes contain a dense actin matrix (Matus et al., 1982; Markham and Fifkova, 1986), we examined the involvement of actin, as well as the Rho family of small GTPases, in the regulation of dendritic remodeling. This family of molecules, of which Rac and Rho are members, is a group of prominent intracellular regulators of signaling pathways that mediate changes in actin organization in response to extracellular cues (Ridley and Hall, 1992; Ridley et al., 1992; Nobes and Hall, 1995). Our results here show that rapid dendritic remodeling is an actin-dependent process and is reciprocally regulated by Rac1 and RhoA that exert mutually antagonistic effects. Thus, these molecules may serve as a nodal point at which extracellular signals can be integrated to regulate precisely dendritic behavior for the establishment and regulation of synaptic contacts.

\section{MATERIALS AND METHODS}

Retinal explant preparation. Embryonic day 12 (E12)-E13 chick embryos were decapitated and enucleated. Eyecups were immersed in oxygenated, 
ice-cold Ringer's solution ( $2 \mathrm{~mm} \mathrm{CaCl}_{2}, 5 \mathrm{~mm} \mathrm{KCl}, 2 \mathrm{mM} \mathrm{MgCl}_{2}, 124 \mathrm{~mm}$ $\mathrm{NaCl}, 1.25 \mathrm{mM} \mathrm{KH}_{2} \mathrm{PO}_{4}, 20 \mathrm{~mm}$ glucose, and $20 \mathrm{~mm}$ HEPES). Retinas were dissected from the eyecups and then mounted on black Millipore filter paper (HABP045) with the ganglion cell layer uppermost as described previously (Wong et al., 1998).

Particle-mediated gene transfection. The mounted retinas were transfected immediately after dissection using the Helios Gene Gun (BioRad, Hercules, CA). In this method, DNA to be transfected is precipitated onto tiny gold particles that are then propelled into the nuclei of cells using a high-pressure helium stream (Lo et al., 1994). The preparation of DNA-coated gold particles was performed according to the manufacturer's recommendations. Typically, for transfections, a total of $1 \mu \mathrm{g}$ of DNA, coated onto $0.5 \mathrm{mg}$ of gold particles (diameter, $1.0 \mu \mathrm{m}$ ), was used in the transfection of each retinal piece. For cotransfection of GFP with the Rac and Rho mutants, DNA coding for GFP (or yellow fluorescent protein; Clontech, Cambridge, UK) and for the small GTPase was mixed in a 1/2.3 ratio and coprecipitated onto the gold particles. The myc-tagged dominant-negative and constitutively active mutants of Rac and Rho were obtained from Dr. Alan Hall (University College, London, UK). Transfections into the ganglion cell layer of the retina were performed at pressures of 30-40 psi, and the retinal explants were subsequently incubated in oxygenated Ringer's solution at $30^{\circ} \mathrm{C}$ overnight. GFP expression was first detected after $6 \mathrm{hr}$, and complete labeling of ganglion cell arbors occurred by $10 \mathrm{hr}$. The retinae remained viable for $>36 \mathrm{hr}$ after transfection, as assessed by dendritic morphology and spontaneous activity. The morphologies of cells obtained with GFP labeling were comparable with those obtained by 1,1'-dioctadecyl3,3,3',3'-tetramethylindocarbocyanine perchlorate (DiI; Molecular Probes, Eugene, OR). This indicates that GFP in the cytoplasm is unlikely to be compartmentalized but is instead distributed throughout the dendritic tree.

Time-lapse imaging. Transfected retinas with labeled cells were transferred to a stage-mounted, temperature-controlled $\left(34^{\circ} \mathrm{C}\right)$ chamber through which oxygenated Ringer's solution was continuously superfused (30-60 ml/hr). Ganglion cells with well resolved arbors were chosen for time-lapse confocal imaging using the Bio-Rad Multiphoton Imaging System (MRC 1024M). GFP-labeled cells were excited using the $488 \mathrm{~nm}$ line of a krypton-argon laser (1-3\% output), and the emitted light was viewed through a $522 / 35 \mathrm{~nm}$ filter. Images of live cells were typically viewed using $40 \times$ [numerical aperture (NA), 0.8] and $60 \times(\mathrm{NA}, 0.9)$ water-immersion objectives (Olympus). Time-lapse images of entire dendritic arbors were reconstructed as a sequence of $z$-projections from stacks of optical sections spanning the entire $z$-dimension of the cell captured every 20-30 min. Rapid time-lapse imaging to follow the continuous movement of individual processes was performed by capturing single-plane images every $3-5 \mathrm{sec}$ with additional electronic zoom factors of two to eight that result in an overall pixel size of $\sim 0.2 \mu \mathrm{m}$ ( $40 \times$ water objective; NA, 0.8; Olympus). In these recordings, however, the confocal aperture was fully open, so that it was possible to distinguish between processes that moved within the $x-y$ plane versus those that traversed out of the plane of focus.

Several observations indicate that the structural changes we describe are not movement artifacts. First, because stacks of confocal images spanning the entire dendritic arbor in all three dimensions were analyzed at each time point, we could reliably determine whether a new terminal dendrite was added, eliminated, extended, or retracted in length. Second, in the fast time-lapse recordings in which a section of the dendritic arbor was imaged with a wide-open aperture, we did not detect significant focal drift in any direction. In these recordings, the primary and secondary branches always remained within the focal plane and exhibited little structural change, whereas small terminal processes showed considerable movements within the $x-y$ plane. There are a few processes that show movements in the $z$-direction and may even move out of the plane of focus, but these can be clearly identified and are not included in our quantitations. In addition, there were also adjacent processes that showed differing movements; one may remain stable, whereas another a few micrometers away shows marked motility. These observations cannot be accounted for by a focus drift in the $z$-direction, as evident from a simple inspection of the movies of such time-lapse recordings (see Fig. 2 for example). Third, the stability of our recordings is also evident in situations in which motility is completely arrested and the processes remained in focus, without any focal readjustments, after superfusion of agents preventing actin polymerization and depolymerization (see results in Fig. 7).

The dendritic movements that we have observed using these imaging methods are also unlikely to arise from deleterious cellular effects resulting from the axotomy of the ganglion cells because we did not observe deterioration in their spontaneous activity or dendritic motility over hours in vitro. In addition, interneurons (amacrine cells) that do not project into the optic nerve also exhibited similar morphological dynamics. The dendritic movements are also unlikely to be induced by phototoxicity. We typically captured images using a laser intensity at least 10 times less than that that results in blebbing changes in dendrites. In addition, the movements occurred immediately after laser scanning and continued at a similar rate throughout the recording period. Importantly, addition of new dendritic processes continued until the end of the recording periods (typically $\sim 3 \mathrm{hr}$ or more in duration). Single images taken at widely spaced times also suggest that morphological changes continue to occur in the absence of frequent irradiation. In addition, the dynamics observed using confocal microscopy were similar to that observed using two-photon microscopy that produces little photodamage (data not shown). We chose to use confocal microscopy to image rapid dynamics because single-plane confocal images captured with a widely open aperture afforded a deeper plane of sectioning than did those obtained using two-photon microscopy. This enabled us to follow more successfully dendritic movements that have a significant length component in the $z$-direction. Finally, the movements were unlikely to be a complication of GFP expression or a result of culturing conditions because DiI-labeled cells in acutely isolated retinae displayed similar dynamics (W. B. Gan, J. Grutzendler, W. T. Wong, R. O. L. Wong, and J. W. Lichtman, unpublished observations).

Calcium imaging. To record spontaneous activity, retinae were loaded with the calcium indicator dye fura-2 AM (Wong et al., 1998) and imaged using two-photon microscopy (excitation wavelength of $775 \mathrm{~nm}$ ). Single optical sections were taken every $3 \mathrm{sec}$, and the changes in fluorescence with time in selected cells were measured using MetaFluor (Universal Imaging Corporation, West Chester, PA). Confocal images of GFPlabeled cells were merged with the fura-2 images to observe structural motility and spontaneous activity in the same cell.

In pharmacological experiments, time-lapse series were collected before and during the superfusion of solutions in which the agents were dissolved. Pharmacological agents were a kainate/AMPA receptor antagonist, 1,2,3,4-tetrahydro-6-nitro-2,3-dioxo-benzo[f]quinoxaline-7sulfonamide (NBQX; Research Biochemicals, Natick, MA), an NMDA receptor antagonist, (+)-2-amino-5-phosphonopentanoic acid (D-APV; Research Biochemicals), NMDA (Sigma, St. Louis, MO), tetrodotoxin (TTX; Sigma), and nickel chloride (Sigma). Inhibitors of actin polymerization, cytochalasin $\mathrm{D}$, cytochalasin $\mathrm{B}$, and latrunculin $\mathrm{A}$, were obtained from Sigma.

Data analysis. Measurements of dendritic process lengths were performed on two-dimensional projections in the $z$-direction. Although the retinal arbors show a general horizontal orientation, this approximation may underestimate the lengths of some of the processes. The analysis of dendritic lengths was performed using image analysis software (Metamorph; Universal Imaging Corporation). To follow the length of a process over time, we measured the distance of the process tip to its base in each image separately. Processes that extended significantly out of the plane of focus (tips became fuzzy) were not included in the analysis. The lifetime of an individual process was estimated to be the total period across a recording that the process was evident. The rate and extent of dendritic movements were computed by following the changes in the length of an individual process across the recording period or, for nonpersistent processes, the duration over which the process was evident. Subsequently, to lower the noise inherent in the measurements (because of exact placement of the cursor at the tip or base, within 1-2 pixels, from measurement to measurement), the length of a process at a single time point was computed as a moving average over three consecutive time points. We calculated the mean rate of an individual process as:

$$
\bar{M}=\sum_{t=0}^{n}\left|\left(L_{t+1}-L_{t}\right)\right| / D,
$$

where $L_{t}$ is the calculated process length at time point $t, n$ is the total number of time points, and $D$ is the total time for which a process was monitored. The average rate for multiple processes followed in this manner was calculated as the average of the mean rates for each process. The instantaneous rate at time $t$ was calculated as:

$$
M_{i}=\left|\left(L_{t+1}-L_{t}\right)\right| / \Delta t,
$$



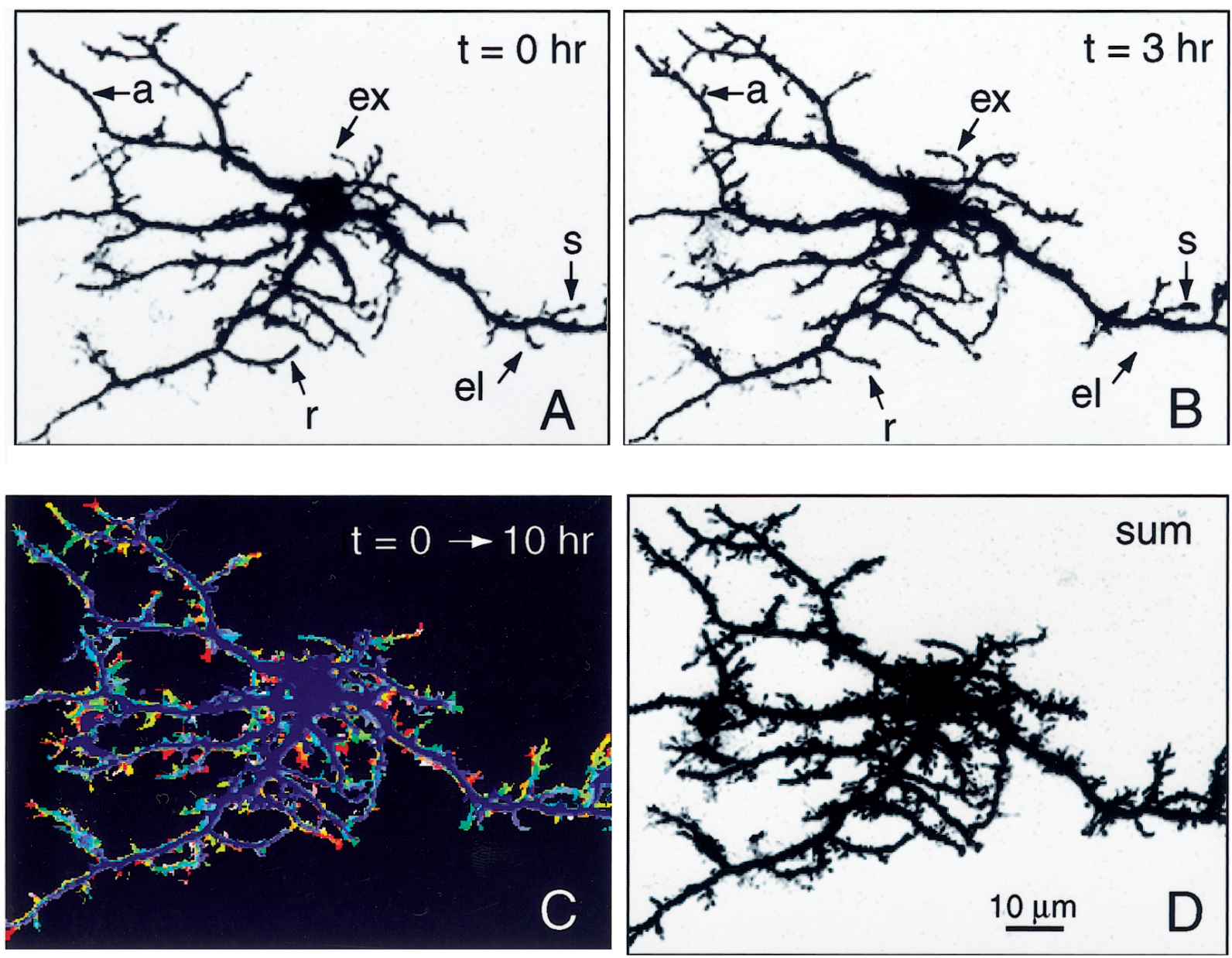

Figure 1. Dendritic remodeling occurs throughout the entire arbor. $A, B$, Extended-focus (z-projection) confocal images of an E12 ganglion cell taken $3 \mathrm{hr}$ apart are shown. Structural changes include extensions $(e x)$, retractions $(r)$, addition of new processes $(a)$, and elimination of previously existing processes $(e l)$. Some processes also remain stable $(s)$ across this period. $C$, Superposition of 21 time-lapse extended-focus images of the same cell, captured at $0.5 \mathrm{hr}$ intervals, for a total recording period of $10 \mathrm{hr}$ is shown. The different colors represent the position occupied by the dendritic tree at different time points, with the cooler colors corresponding to earlier time points and the warmer colors to later ones. A movie (dendrite.avi) of the consecutive frames can be viewed at http://thalamus.wustl.edu/wonglab/images/dendrite.avi. $D$, The sum of all 21 images marks all the positions in space traversed by dendritic processes during the recording period. The dendritic volume occupied by the cumulative image in $D$ is markedly greater than that of the instantaneous image in $A$.

where $\Delta t$ is the interval between time points. The average or mean rate of movement across a population of processes is simply the sum of the individual rates divided by the number of processes. The extent of movement across the recording period $(250 \mathrm{sec})$ was computed as the difference between the maximum and minimum observed lengths for a particular process. The average extent of movement (averaged across a population of processes) is the sum of the individual "extents" divided by the number of processes.

\section{RESULTS}

\section{Dendritic remodeling in ganglion cells is extensive and rapid}

Our recordings reveal an extensive reorganization of dendritic structure that is appreciable between consecutive frames $(n=30$ cells examined). At $0.5 \mathrm{hr}$ intervals, for a total of $10 \mathrm{hr}$, dendritic changes were comprised of extensions and retractions of processes, as well as the addition of new processes and the elimination of existing processes (example shown for two time points in Fig. 1A,B). These different forms of reorganization occurred simultaneously in all parts of the dendritic tree and were robust for the duration of the recording (Fig. 1C). A superposition of the images captured across the recording period demonstrates that the extent, rate, and distribution of dendritic movements allow dendritic processes to traverse in a few hours a much larger volume in space than that occupied at any single point in time (Fig. 1, compare $A, D$ ). In addition, this figure illustrates how dendritic motility is primarily restricted to tertiary branches; primary and secondary branches move little if at all, and the overall shape of the arbor is not greatly affected by the motility of its terminal branches.

Subsequently we obtained images of the dendrites at more frequent time intervals to determine whether the structural changes we observed across the arbor actually occurred more rapidly. To follow the changes in structure completely, we captured confocal images of individual dendritic processes at high magnification, every 3-5 sec over a period of 4-16 min. In these recordings, the confocal aperture was fully opened, so that processes leaving the plane of focus could be distinguished from those that remained within the focal plane during the period of recording. Over 100 such recordings were obtained. Figure $2 A$, left, shows a portion of a dendritic arbor followed in this way. These fast time-lapse recordings revealed that most processes 

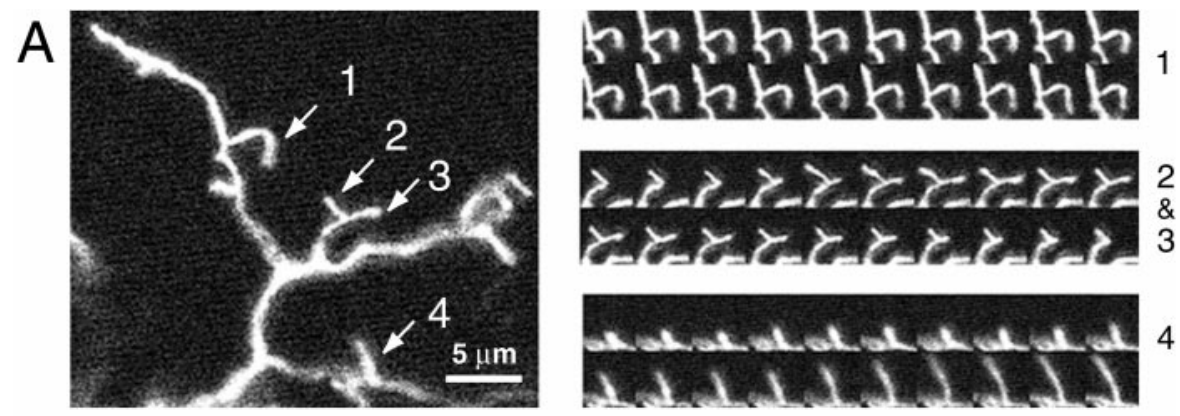

B
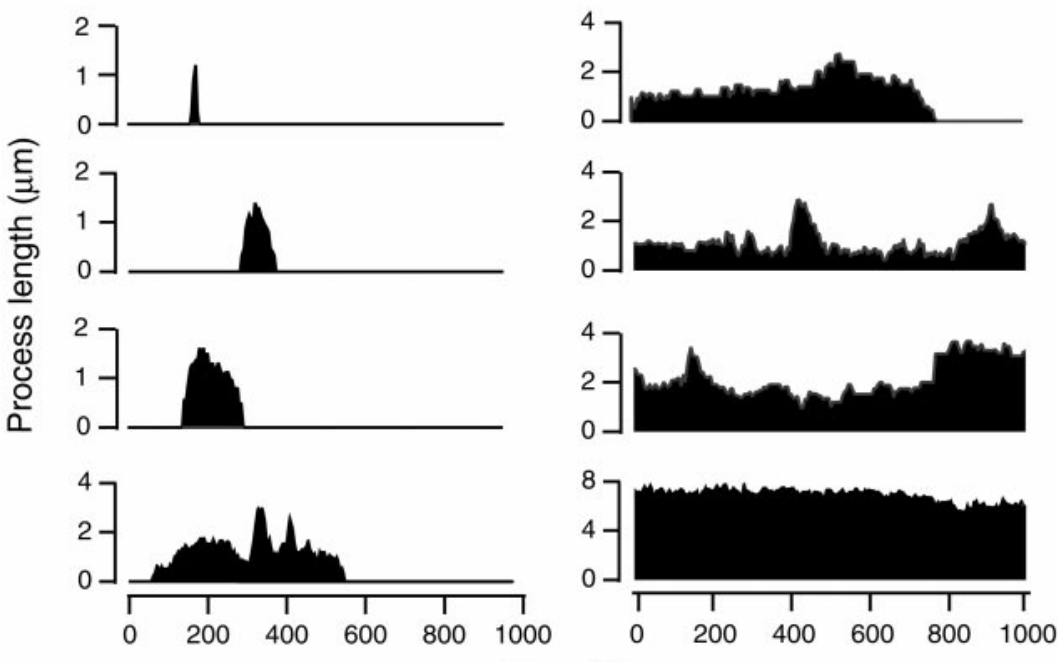

Time (s)
Figure 2. Movements of individual dendritic processes are highly rapid and diverse. A, Left, Confocal image of a dendritic branch of an E12 ganglion cell captured at high magnification. Right, Time-lapse images of processes on the same primary dendrite, indicated by arrows in the left panel. The interval between frames is $10 \mathrm{sec}$. Process 1 is relatively stable. Adjacent processes show motility of different kinds, with process 2 exhibiting small changes in its length in the same time that process 3 appears de novo and then retracts completely. Process 4 is an example of a continuous and progressive extension. A movie (filopodia. avi) of the consecutive frames can seen at http:// thalamus.wustl.edu/wonglab/images/filipodia.avi. $B$, Length-versus-time plots for eight other representative processes from different parts of the cell shown in $A$ (left), illustrating the diversity and rate of dynamic movements. changed markedly in length and shape over seconds. Neighboring processes on a dendritic branch exhibited varied behaviors; addition, extension, elimination, and retraction of processes were observed (Fig. $2 A$, right). A minority $(\sim 6 \%)$ of processes, however, remained relatively stationary (rate $<0.5 \mu \mathrm{m} / \mathrm{min}$ ) throughout the period of observation. In addition, individual processes were moved at different rates and directions during the course of the recording. Also, although some processes persisted throughout the recording period, others were transient. Figure $2 B$ illustrates the behavior of eight processes from a single dendritic arbor during a $1000 \mathrm{sec}$ recording period. In all recordings, individual processes appeared to behave independently irrespective of their neighbors.

Having observed continuous movements in each process, we used two parameters to quantify their dynamics. First, we calculated the rate of movement, which is the sum of the length changes exhibited by a process across the recording period divided by the time that the process was present (defined mathematically in Materials and Methods). This parameter gives an indication of how quickly a particular process moves. Second, we measured the extent of movement, which is defined as the difference between the maximum and minimum lengths exhibited by a process across the recording period of $250 \mathrm{sec}$. This parameter reflects the "reach" achieved by a process over a few minutes.

The rate of movement averaged across 188 processes from 14 cells was $1.33 \pm 0.89 \mu \mathrm{m} / \mathrm{min}$ (mean $\pm \mathrm{SD}$ ). Mean rates for individual processes ranged up to $5 \mu \mathrm{m} / \mathrm{min}$, and maximum instantaneous rates (see Materials and Methods) reached 10 $\mu \mathrm{m} / \mathrm{min}$. The average extent of movement by a process over this period was $1.88 \pm 1.53 \mu \mathrm{m}$, which is $\sim 50 \%$ of the average process length $(3.91 \pm 3.30 \mu \mathrm{m} ; n=100)$. Moreover, if we estimate a process to have a cross-sectional area of $0.5 \mu \mathrm{m}^{2}$, then the tip of an average process would traverse in $250 \mathrm{sec}$ a volume of 0.94 $\mu \mathrm{m}^{3}\left(0.5 \mu \mathrm{m}^{2} \times 1.88 \mu \mathrm{m}\right), 50 \%$ of the volume of an average process $\left(0.5 \mu \mathrm{m}^{2} \times 3.91 \mu \mathrm{m}=1.96 \mu \mathrm{m}^{3}\right)$. By moving at the average rate of $1.33 \mu \mathrm{m} / \mathrm{min}$, the dendrite would sample each portion of that volume approximately three times in $250 \mathrm{sec}$ $(1.33 / 1.88 \times 250 / 60=2.95)$. Although imprecise, these calculations show that dendritic movements enable processes to cover an expanded volume around themselves (illustrated also in Fig. 1D), potentially increasing the probability of contact with nearby afferents.

\section{Restructuring events are balanced across the dendritic arbor}

How do the rapid dendritic movements that occur over seconds to minutes relate to the change in the overall size and complexity of the dendritic arbor over hours? To address this issue, we monitored changes in entire arbors by capturing images every $20 \mathrm{~min}$ for $3 \mathrm{hr}(n=4$ cells). We observed that the number and the size of additions to the arbor in each interval were closely matched to the number and the size of the losses (example shown in Fig. $3 A-C)$. To test the possibility that an apparent balance actually reflects separate large areas of addition and elimination of processes, we calculated the number of branch points of the arbor separately for the central and peripheral halves of each cell. 


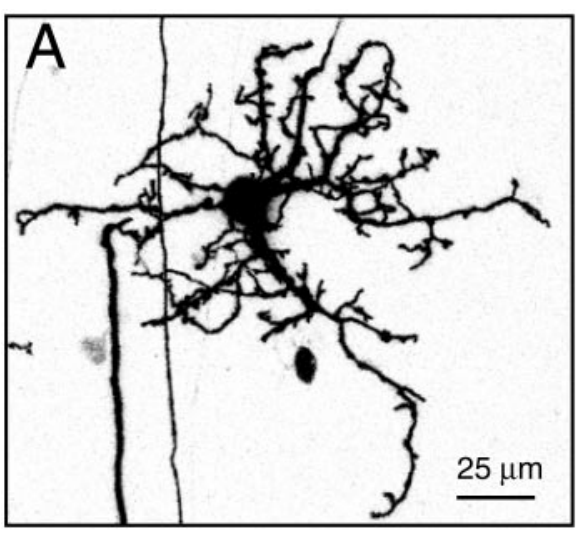

D

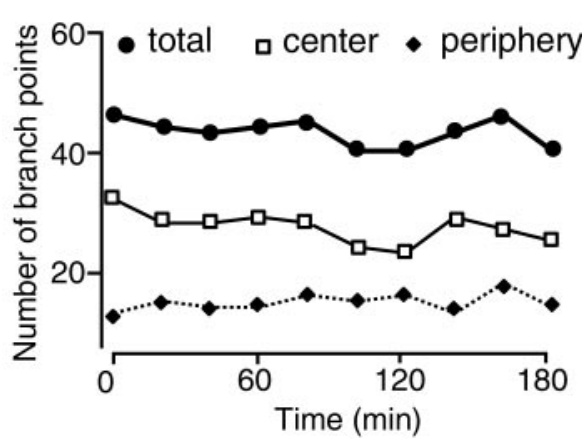

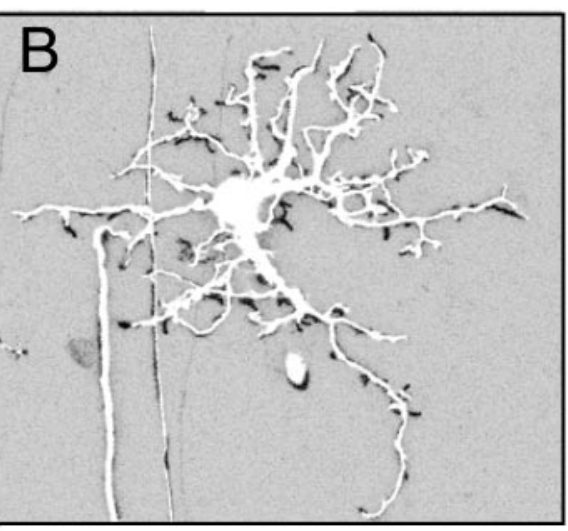

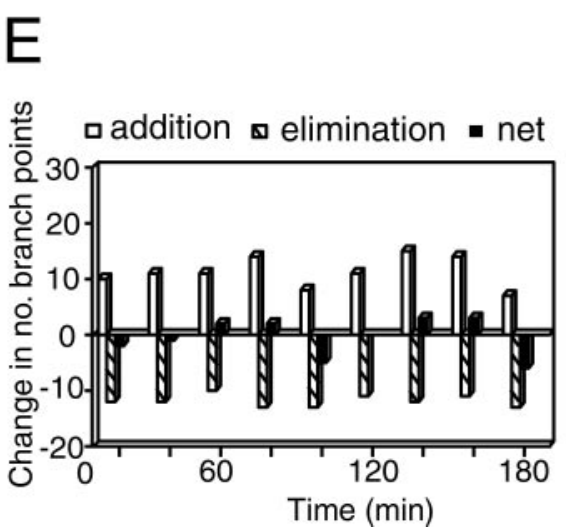

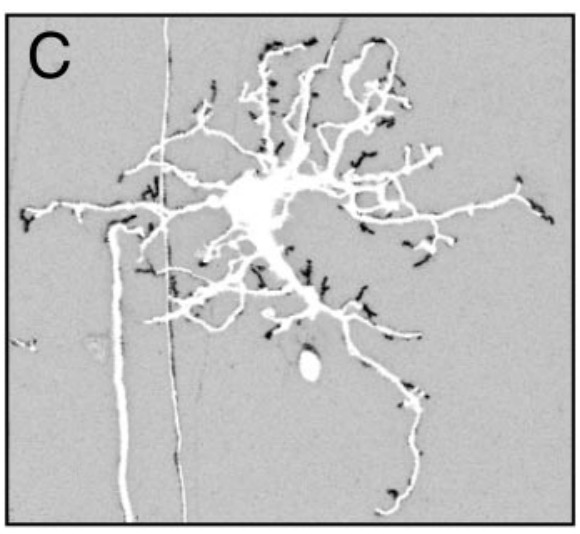

$\mathrm{F}$

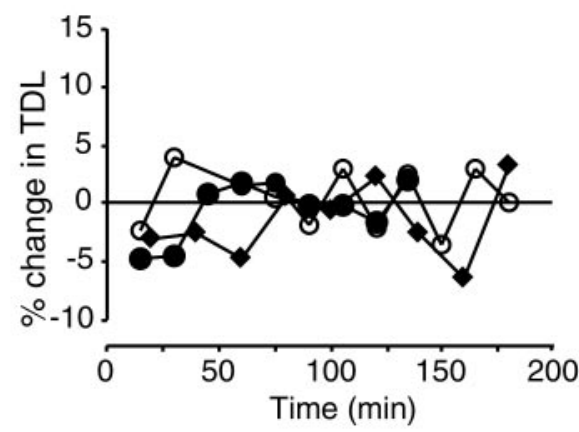

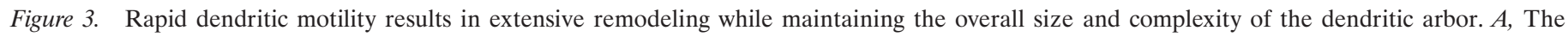

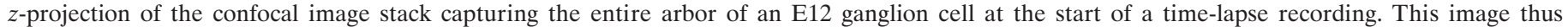

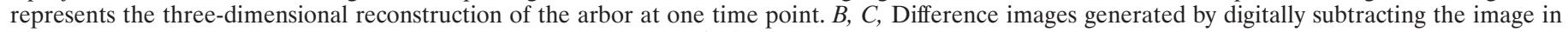

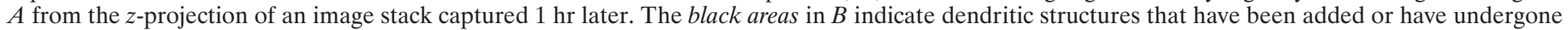

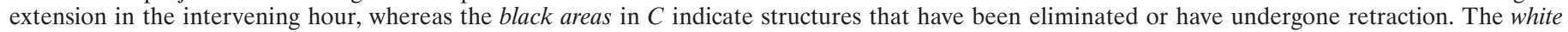

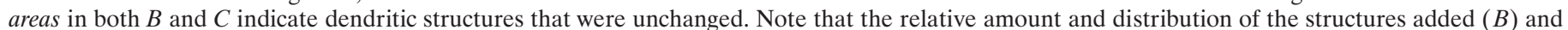

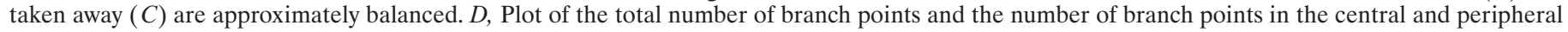

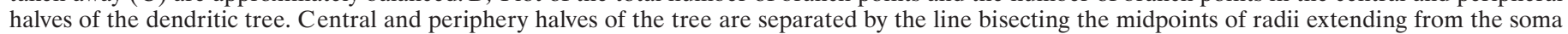

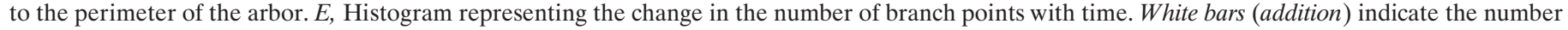

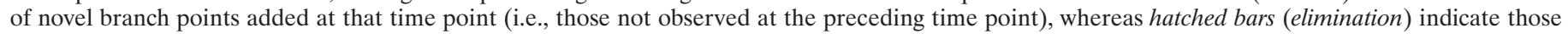

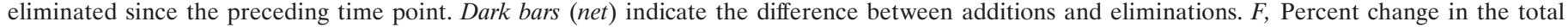

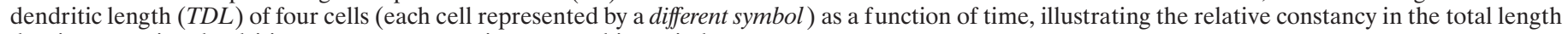
despite extensive dendritic movements occurring across this period.

Although many branch points were added and eliminated between consecutive time points, the net change in the overall number of branch points in both the central and peripheral halves of the arbor was close to zero (Fig. $3 D, E$ ). This trend is also present in the total dendritic length of the arbor (Fig. $3 F ; n=4$ cells); the net change in dendritic length between the time points was small compared with the total dendritic length of the tree (averaging $3.25 \pm 0.95 \%$ for four cells over the periods of recording). Thus, despite considerable local change over seconds, the total dendritic length remained surprisingly constant over the time scale of a few hours. Taken together, our results indicate that the rapid restructuring is balanced across the arbor to maintain relatively constant not only the size but also the complexity of the tree over the time scale of a few hours. Although dendritic trees appeared immature at this stage (E12-E13) in comparison with those in the posthatchling (Thanos et al., 1992), we estimate that the overall growth and elaboration of the ganglion cell dendritic arbor proceed at a much slower rate (many hours to days) than the rate of dendritic remodeling (seconds to minutes). Therefore, the rapid movements observed on a short time scale do not result in a rapid net growth and elaboration of the dendritic tree but rather serve to distribute dendritic processes rapidly throughout the space around the arbor.

\section{Dendritic motility is developmentally regulated}

To determine whether the rapid dendritic movements observed in E12-E13 retinal ganglion cells are a feature of immature cells undergoing synaptogenesis, we compared the motility of the dendrites in this early age group with that in older retina at a stage when synaptogenesis in the inner plexiform layer is relatively more advanced (E15-E16) (Hughes and LaVelle, 1974; Hering and Kröger, 1996). It is evident from Figure 4 that, although many processes at E12-E13 moved at rates $>2.0$ $\mu \mathrm{m} / \mathrm{min}$, at E15-E16, the processes moved at rates below this value. Processes from E12 to E13 cells moved at an average rate of $1.54 \pm 0.11 \mu \mathrm{m} / \mathrm{min}( \pm \mathrm{SE})$, whereas at E15-E16, the average rate was $0.84 \pm 0.04 \mu \mathrm{m} / \mathrm{min}$. The difference in the average rate of movement between these two age groups was also statistically significant (Mann-Whitney $U$ test, $p<$ 0.0001). Thus, the dendritic motility appears to be developmentally regulated, being prominent during the time of active 

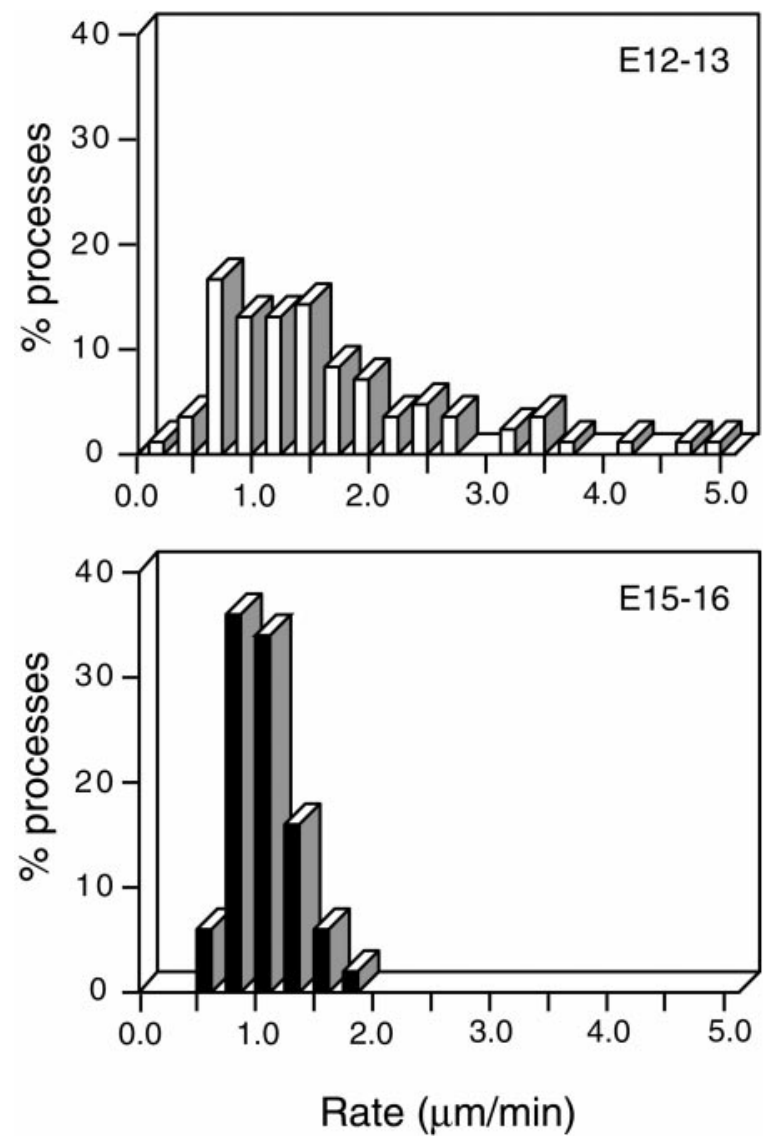

Figure 4. Developmental regulation of dendritic motility. Frequency histograms showing the distribution of the rates of movements of dendritic processes of cells from two periods of development [E12-E13 (top); E15-E16 (bottom)]. The number of cells $=9$ for E12-E13 and 8 for E15-E16; the number of processes $=83$ for E12-E13 and 50 for E15-E16.

synaptogenesis, but becomes downregulated as synapses form and mature.

\section{Dendritic remodeling occurs in spontaneously active cells}

In previous studies, we showed that retinal ganglion cells at the ages studied here exhibit spontaneous rhythmic-bursting activity that propagates horizontally across the retina in the form of waves (Wong et al., 1998). To confirm that rapid dendritic change occurs in cells that are physiologically intact and that neurotransmission continues in the retinae after biolistic delivery of the particles, we used two-photon calcium imaging to examine the activity of cells in the GFP-transfected retinae. We found that GFP-labeled ganglion cells fired in synchrony with their untransfected neighbors (Fig. 5). Thus the restructuring events we observed are likely to be representative of those occurring in intact circuits. In addition, it raises the possibility that the structural changes we observed may be regulated by neurotransmission between retinal interneurons and the ganglion cells.

\section{Afferent glutamatergic signaling regulates dendritic remodeling}

Retinal ganglion cells at the ages studied (E12-E13) receive excitatory glutamatergic inputs from bipolar cells. These excitatory inputs drive the endogenous rhythmic-bursting activity exhibited by ganglion cells (Wong et al., 1998; Wong, 1999; Sernagor et al., 2000). Antagonists of ionotropic glutamate receptors

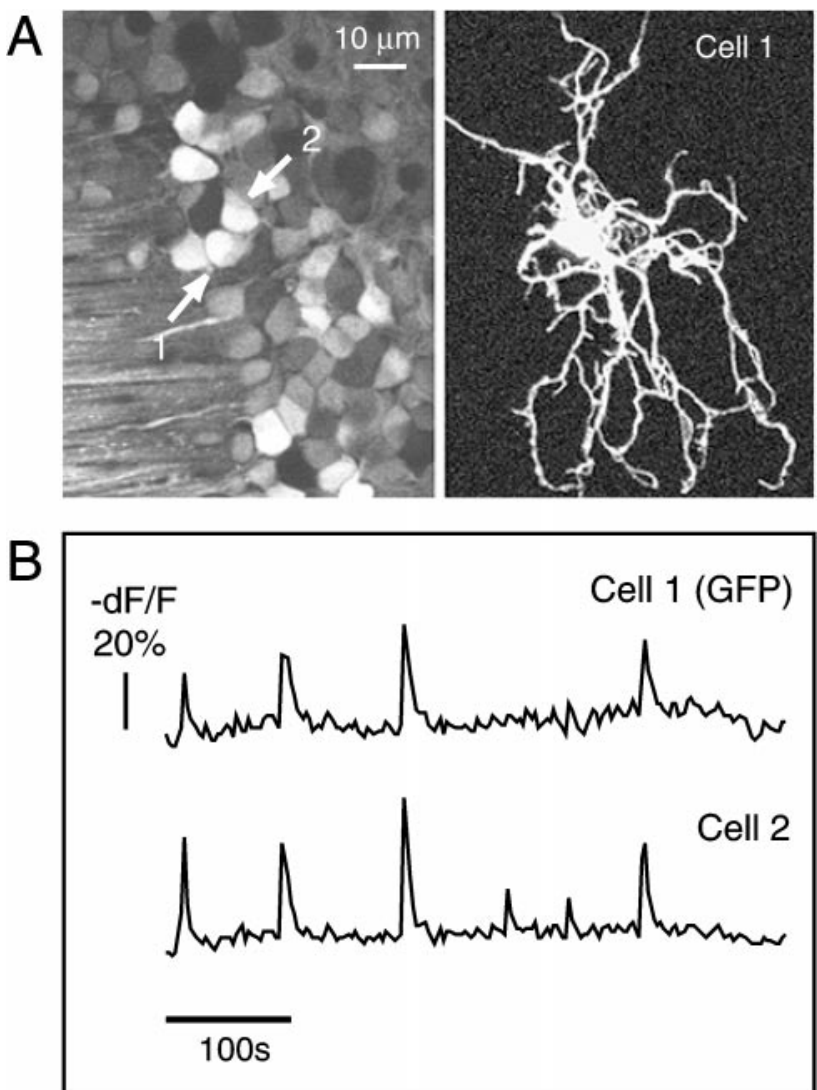

Figure 5. Dendritic remodeling occurs in intact, endogenously active retinal circuits. $A$, The field of cells in the ganglion cell layer of a transfected E13 retina that was loaded with the calcium-sensitive dye fura-2 AM is shown. Fura-2 AM labeling was visualized using twophoton microscopy (left), whereas GFP expression in the same field was visualized using confocal microscopy (right). Alignment of the two fields was confirmed by using a sample that can be detected by both recording modes. Arrows indicate a GFP-labeled cell (Cell 1) and a neighboring untransfected cell (Cell 2). Cell 1 exhibited dendritic changes as confirmed by time-lapse confocal imaging. $B$, GFP-labeled cells (Cell 1) retained their endogenous pattern of spontaneous bursting activity, as indicated by patterns of rhythmic $\left[\mathrm{Ca}^{2+}\right]_{\mathrm{i}}$ elevations that were similar to those in the untransfected cells (Cell 2). $\mathrm{dF} / \mathrm{F}$ indicates percent change in fluorescence intensity.

(10 $\mu \mathrm{M}$ NBQX and $100 \mu \mathrm{M}$ D-APV, selective antagonists of non-NMDA and NMDA glutamate receptors, respectively) suppress this bursting activity (Fig. 6A).

This blockade resulted in a decrease in the number of branch points $(60 \pm 12 \%$ of controls; $n=6$ cells $)$ and in the total dendritic length in ganglion cells (Fig. 6B,D). Remodeling events in the absence of glutamatergic transmission are not completely arrested; however, the numbers of dendritic additions (scored as the number of processes that elongate or are added de novo) and reductions (the number of processes that shorten or are eliminated) are both decreased (Fig. 6C). Moreover, the balance between processes added and taken away is no longer maintained; reductions outnumber additions (Fig. $6 C$ ), resulting in a net decrease in the amount of dendritic material with time (Fig. $6 D$; Mann-Whitney $U$ analysis for the effect of antagonist on the total dendritic length, $p<0.0001$ ). The decrease in total dendritic length occurs progressively across the period of blockade (up to $50 \mathrm{~min}$ ) and recovers partially after a prolonged washout of an hour (data not shown) (see also Rajan and Cline, 1998; Rajan et al., 1999). 


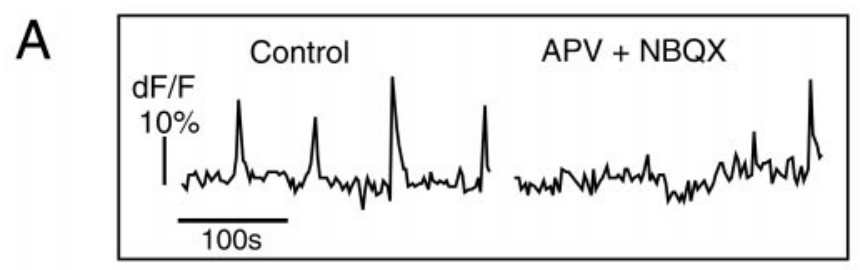

B
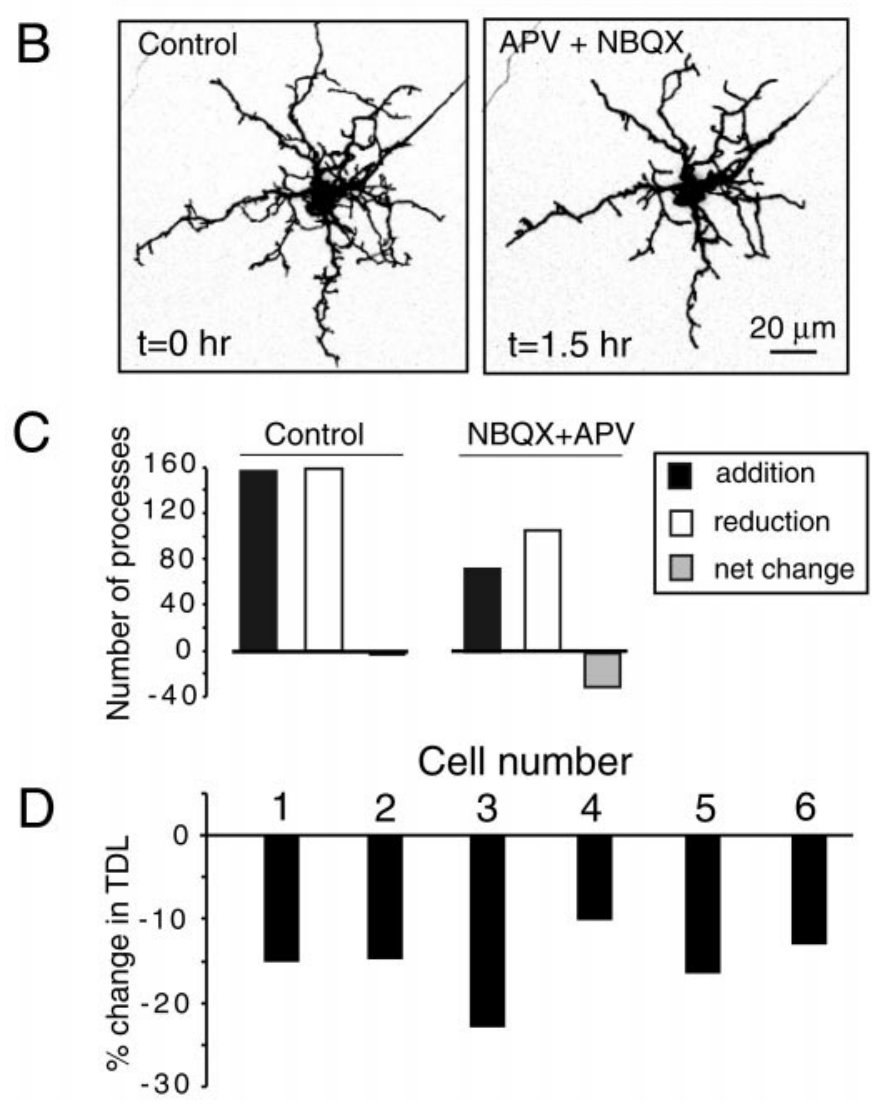

\section{E Extent}
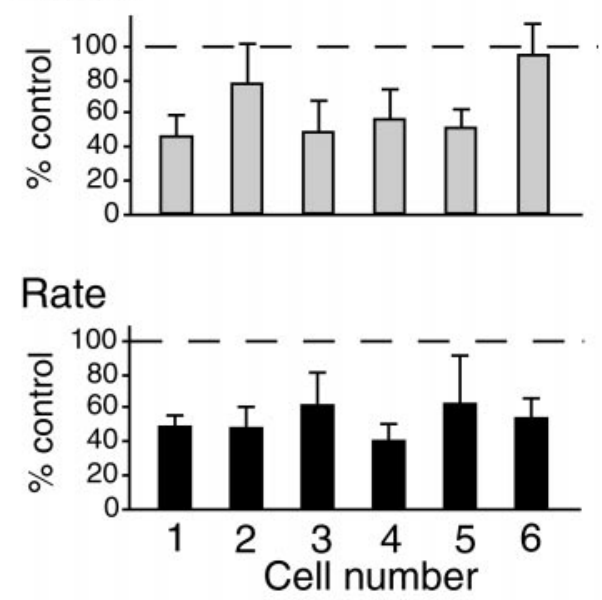

F Extent
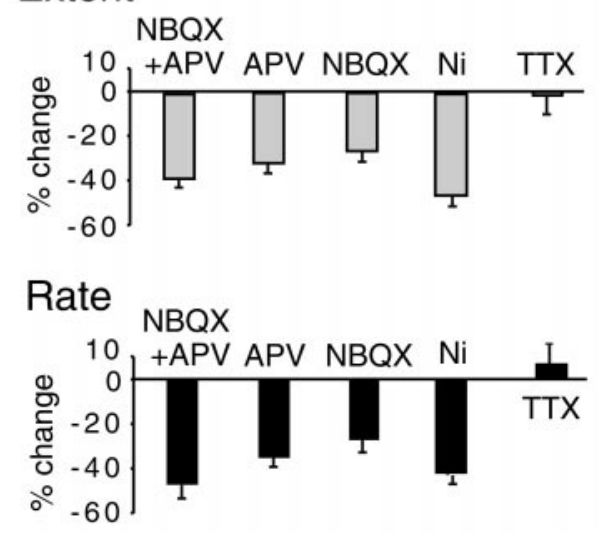

Figure 6. Dynamic dendritic remodeling is regulated by endogenous ionotropic glutamatergic transmission. $A$, Calcium recording showing rhythmic spontaneous activity in an E12 retinal ganglion cell and a suppression of this activity in the presence of the ionotropic glutamate antagonists NBQX (10 $\mu \mathrm{M})$ and D-APV $(100 \mu \mathrm{M}) . B$, $z$-projection of the confocal image of an E12 ganglion cell before (left) and $1.5 \mathrm{hr}$ after (right) the application of NBQX $(10 \mu \mathrm{M})$ and D-APV $(100 \mu \mathrm{M})$. C, Changes in the number of terminal processes undergoing growth versus retraction before (left) and during (right) glutamatergic blockade. For the cell shown in $B$, the total number of growing processes (comprising existing processes that elongate or are formed de novo; black bars) was compared with the total number of retracting processes (comprising existing processes that shorten or are eliminated; white bars) in a $1 \mathrm{hr}$ period. Gray bars indicate the difference between the growing and retracting processes. $D$, The percent change in total dendritic length for six cells before and $30 \mathrm{~min}$ after application of NBQX $(10 \mu \mathrm{M})$ and D-APV $(100 \mu \mathrm{M})$. E. Blockade of ionotropic glutamatergic transmission decreases the motility of individual terminal processes. Histograms indicate the rate and extent of movement of individual processes as a percentage of control values after $30 \mathrm{~min}$ of drug application in six E12-E13 retinal ganglion cells (number of processes $=100$ in control and 59 in drug). Statistical analyses [SAS/STAT (SAS, 1996)] for the entire population showed a significant reduction for both extent $(p=0.0177)$ and rate $(p=0.0017) . F$, Summary of the effect of different antagonists on the motility of individual processes. Histograms indicate the percentage change in the extents and rates of movement 15-30 min after the application of the compound. Applications of NBQX $(10 \mu \mathrm{M})$ and D-APV $(100 \mu \mathrm{M})$ together $(100$ processes in control; 59 processes in drug; 6 cells), D-APV alone (100 $\mu \mathrm{M} ; 85$ processes in control; 55 processes in drug; 3 cells), NBQX alone (10 $\mu \mathrm{M} ; 84$ processes in control; 63 processes in drug; 3 cells), and $\mathrm{Ni}^{2+}(5 \mathrm{mM} ; 74$ processes in control; 43 processes in drug; 3 cells) all significantly reduced the extent and rate of movement ( $p<$

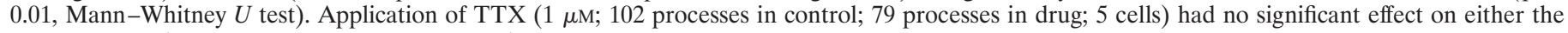
extent or rate $(p>0.25$, Mann-Whitney $U$ test $)$.

We found that the dynamics of individual dendritic processes were also regulated by glutamatergic transmission. The dynamics were unchanged immediately after the application of the antagonists NBQX and D-APV, but after 15-30 min in glutamatergic blockade, both the extent and the rate of movement were reduced compared with control (Fig. 6E). This effect is likely to be mediated via both NMDA and non-NMDA glutamate receptors because separate applications of D-APV (100 $\mu \mathrm{M})$ and NBQX (10 $\mu \mathrm{M})$ each significantly reduced both the extent and the rate of movement (Fig. 6F). The influx of extracellular calcium via voltage-gated calcium channels may also be important in potentiating the dynamics of processes because blockade of voltagesensitive calcium channels with $\mathrm{Ni}^{2+}(5 \mathrm{~mm})$ (Yuste and Denk, 1995) suppressed motility (Fig. $6 F$ ). Interestingly, the elimination of sodium action potentials by the application of TTX $(1 \mu \mathrm{M}) \mathrm{did}$ not change either the rate or the extent of dendritic movements. Because bipolar cells have graded membrane potentials and do not depend on axonal action potentials for neurotransmitter release (Rodieck, 1998), TTX is unlikely to affect afferent glutamatergic signaling from bipolar cells to ganglion cells. However, 
TTX inhibits voltage-gated sodium channels, blocking spontaneous bursting activity in retinal ganglion cells (Wong et al., 1995) and the propagation of dendritic action potentials in other neurons (Yuste and Tank, 1996). Dendritic motility is therefore not regulated as a function of spiking activity on the level of the cell body, nor is it dependent on the spread of sodium action potentials into dendritic processes.

Together, our results indicate that glutamatergic signaling onto dendrites is important in regulating the motility in individual dendrites, as well as in maintaining the overall size and complexity of the dendritic arbor by controlling the balance between the addition and removal of dendritic processes. This effect is mediated via both NMDA and non-NMDA receptors and is dependent on calcium influx but not on sodium channel-mediated action potentials.

\section{Dendritic remodeling is an actin-dependent process}

Terminal dendritic processes are devoid of microtubules but contain a dense actin matrix (Matus et al., 1982; Markham and Fifkova, 1986; Fiala et al., 1998), and rapid alterations in the shape of mature dendritic spines depend on actin polymerization (Fischer et al., 1998). As a first step in elucidating the intracellular mechanisms that regulate dendritic remodeling, we asked whether the actin cytoskeleton is also required for dendritic motility. We thus applied drugs that interfere with actin polymerization. Figure $7 A$ shows the degree of dendritic remodeling in a branch before (left) and after (right) the addition of cytochalasin D (500 nM), a drug that binds to the fast-growing end of actin filaments and inhibits their growth and disassembly (Cooper, 1987). Application of this drug results in a rapid arrest in motility of dendritic processes (one example is shown in Fig. 7B). This effect was reversible after washout (data not shown). All filopodia investigated in this way behaved similarly regardless of their initial motility before drug application (Fig. 7C). Two other drugs, cytochalasin B $(1 \mu \mathrm{M})$, which acts similarly to cytochalasin D (Cooper, 1987), and latrunculin A (100 ng/ml), which inhibits actin polymerization by sequestering actin monomers (Spector et al., 1989), were also effective in arresting dendritic motility (data not shown). These results suggest that rapid dendritic dynamics are driven by changes in the polymerization of actin.

\section{Dendritic remodeling is regulated by Rho and Rac}

Members of the Rho family of small GTPases are components of intracellular pathways via which extracellular influences organize the actin cytoskeleton (Tapon and Hall, 1997; Van Aelst and D'Souza-Schorey, 1997; Hall, 1998). These molecules are expressed by many parts of the nervous system, including the developing chick retina (Malosio et al., 1997). We therefore evaluated the role of two subfamilies within the family, the Rho and Rac proteins, in regulating actin-dependent dendritic remodeling. We transfected retinal ganglion cells with expression plasmids encoding mutant proteins that increase or decrease Rho or Rac activity. Endogenous forms of Rho and Rac cycle between a GDP-bound inactive form and a GTP-bound active form. Constitutively active mutants of Rac1 and RhoA (ca-V12 Rac1 and ca-V14 RhoA; abbreviated in this manuscript Rac+ and Rho+) are unresponsive to regulatory proteins that trigger the hydrolysis of GTP to GDP and thus are permanently in the activated state (Ridley et al., 1992). Dominant-negative mutants (dn-N17 Rac1 and dn-N19 RhoA; abbreviated Rac- and Rho-) bind irreversibly to the specific intracellular factors mediating the exchange of GDP for GTP, thus preventing the activation of endogenous
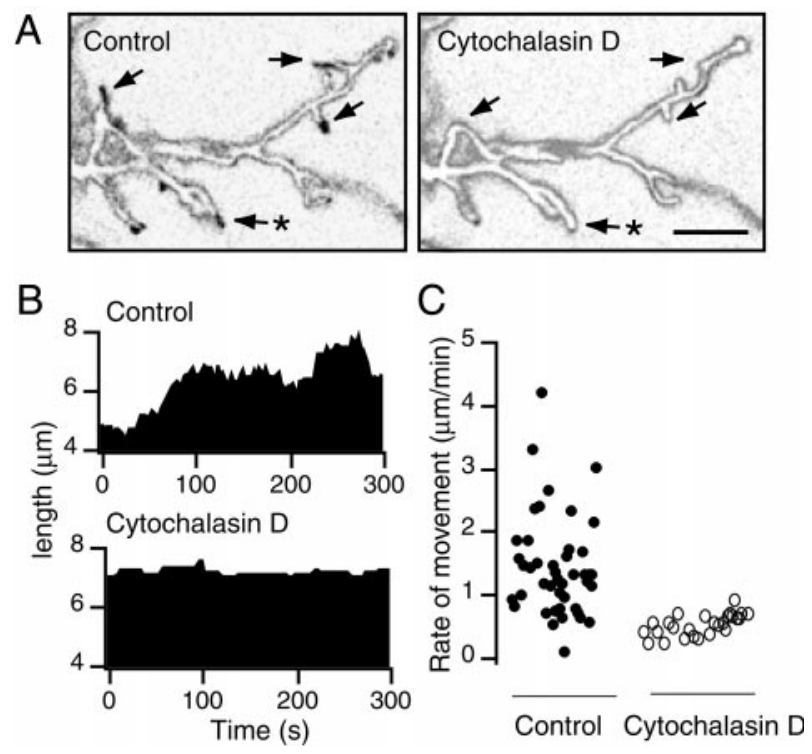

Figure 7. Rapid dendritic remodeling is dependent on actin polymerization. A, Left, Difference image of a dendritic branch of an E12 ganglion cell generated by subtracting two confocal images taken 5 min apart under control conditions. Black areas (indicated by arrows) indicate regions of structural change (dendrites that have been either added or eliminated in the intervening $5 \mathrm{~min}$ period). Right, Difference image of the same dendritic branch generated by similarly subtracting two confocal images taken 5 min apart after the application of cytochalasin D (500 nM). Note the absence of black profiles, indicating a reduction in the amount of dendritic restructuring in the same time period when actin polymerization is arrested. Scale bar, $5 \mu \mathrm{m}$. $B$, Length-versus-time plots for the process indicated by the asterisk in $A$ before (top) and after (bottom) the application of cytochalasin D. The actively extending and retracting process becomes relatively stationary after drug application. $C$, Average rates of individual processes in three separate recordings at E12-E13 before (left) and after (right) the introduction of cytochalasin D. The wide range of motilities exhibited by individual processes under control conditions is replaced by uniform stability after the arrest of actin polymerization (number of processes, control $=41$; cytochalasin $\mathrm{D}=26$ ).

forms of Rac or Rho (Diekmann et al., 1991). Mutant RhoA and Rac1 proteins might affect multiple Rho and Rac isoforms, respectively, so we ascribe their effects to Rho and Rac generally, and not specifically. In each case, the Rho or Rac mutant was cotransfected with DNA encoding GFP in a 2.3/1 (GTPase/GFP) ratio. The constructs were tagged with the myc-epitope, and reliable contransfection was confirmed by post hoc immunohistochemistry in GFP-labeled cells (data not shown). Transfected ganglion cells were evaluated $18-24 \mathrm{hr}$ after biolistic delivery.

We were first concerned that the upregulation or downregulation of these key regulatory proteins might have deleterious effects on the physiology or morphology of transfected cells. We therefore evaluated the endogenous activity of transfected cells using calcium imaging with fura-2 AM. Retinal waves persisted in the transfected retinae, and transfected cells exhibited the same pattern of spontaneous rhythmic bursting seen in neighboring untransfected cells (data not shown; records were qualitatively similar to those shown in Fig. 5). This indicated that the transfected cells were physiologically active and remained in communication with neighboring cells. Moreover, transfected ganglion cells maintained an elaborate arbor and did not show indications of deleterious effects such as swollen cell bodies, dendritic varicosities, and pyknosis (Fig. 8). There were, however, some morphological differences between transfected ganglion cells and 

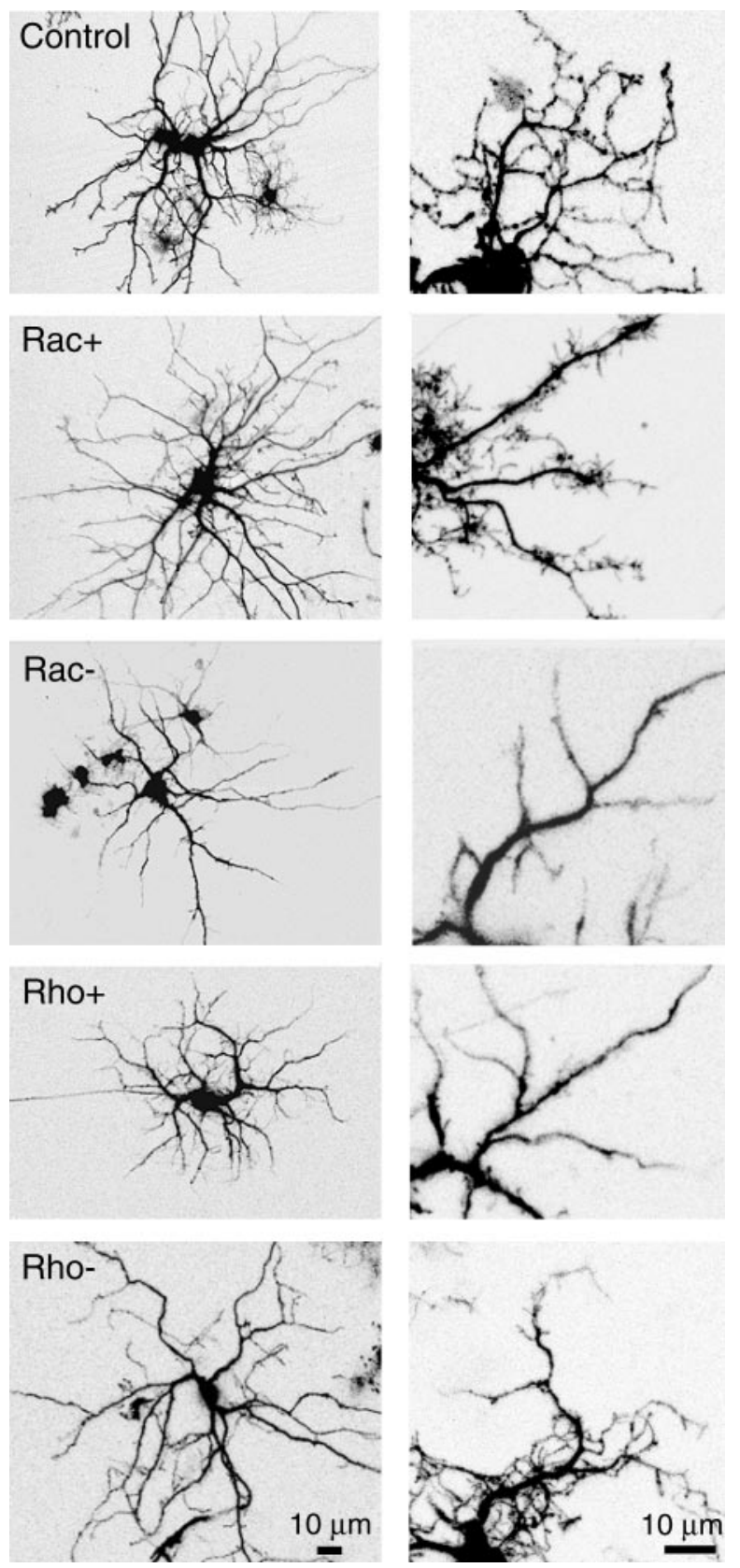

Figure 8. Rac and Rho regulate the dendritic architecture of retinal ganglion cells. Representative dendritic arbors (left column) and higher magnification views of the dendritic structure (right column) of E12-E13 ganglion cells expressing GFP alone (control) or expressing both GFP and constitutively active $(\mathrm{Rac}+, \mathrm{Rho}+)$ or dominant-negative ( $\mathrm{Rac}-, \mathrm{Rho}-)$ forms of Rac or Rho. Expression of Rac+ increases the density of fine terminal processes, whereas expression of Rac- reduces it. Expression of $\mathrm{Rho}+$ results in a morphology similar to that in $\mathrm{Rac}-$, whereas dendritic arbors expressing Rho- are similar to that in the control.

their controls. Rac+-expressing ganglion cells tended to have fewer secondary and tertiary branches but an increased number of short terminal processes. Conversely, Rac- and Rho+ cells had arbors that exhibited secondary and tertiary branching but had fewer small terminal processes. These structural effects resembled those observed by Ruchhoeft et al. (1999). Cells expressing Rhowere qualitatively more similar to those in controls. In any event, terminal dendritic processes remained motile, thus allowing us to assess the role of these GTPases in regulating the dynamics of their remodeling behavior.

Fast time-lapse imaging revealed significant effects of Rac and Rho activity on the rapid remodeling of dendritic processes. In general, dominant-negative and constitutively active mutants of each of the GTPases had opposite effects on dendritic motility. Moreover, the effects of Rac and Rho perturbations were also opposite in nature. We used the parameters of rate and extent, defined above, to quantitate the dynamics of each process. Figure $9 A$ shows the frequency distribution of average rates and extents for individual processes in the background of upregulated and downregulated Rac and Rho function; the net effects are summarized in Figure 9B. Expression of Rho+ decreased both the rate and the extent of movements, whereas expression of Rhoincreased both the rate and the extent. Modulation of Rac function produced opposite results. Rac- decreased both the rate and the extent of motility, whereas Rac + increased both parameters slightly. Although the effects of Rac + were not statistically significant, the effects of Rac-, Rho+, and Rho- were all highly significant ( $p<0.001$, Mann-Whitney $U$ test). Evaluated together, the opposite effects of Rho and Rac activity and, in particular, the similarity in the effects of the downregulation of Rac and the upregulation of Rho suggest that Rac and Rho act reciprocally to regulate rapid dendritic remodeling.

For a third measure of dendritic dynamics, we measured how Rho and Rac regulate the turnover of processes (Fig. 9C). Upregulating Rac function resulted in an increased turnover of processes; in cells expressing $\mathrm{Rac}+$, the proportion of processes persisting across the recording period (lifetime $>250 \mathrm{sec}$ ) decreased (48\% compared with $75 \%$ in the control), whereas the proportion of short-lived processes $(0-125 \mathrm{sec})$ doubled (23 vs $10 \%)$. Conversely, attenuation of Rac function by expression of $\mathrm{Rac}-$ increased the proportion of persistent processes (87 vs $75 \%$ ) and decreased that of short-lived processes (6 vs 10\%). Modulation of Rho function had effects opposite to those of Rac; constitutively active Rho increased the fraction of persistent processes, whereas dominant-negative Rho decreased the fraction slightly. These results suggest that as in the case for the rate and extent of process movements, endogenous Rac and Rho exert reciprocal effects on the rate at which processes are eliminated and replaced by new ones (Fig. 10).

\section{DISCUSSION}

\section{Rapid dendritic motility in developing dendrites}

Our observations revealed a surprisingly high degree of endogenous motility in developing dendrites, with rates that exceed those recorded in other systems (Dailey and Smith, 1996; Ziv and Smith, 1996). This may reflect intrinsic differences between systems; alternatively, the motility in retinal ganglion cell dendrites may be potentiated by the prominent spontaneous activity preserved in our whole-mount retinal preparations. Dendritic movements lacked synchrony with each other and were collectively balanced across the arbor to maintain the overall arbor size and complexity. Structural changes were primarily confined to terminal dendritic processes; primary and secondary dendritic trunks were comparatively stable in structure and position. Taken together, the characteristics of these movements suggest that they are unlikely to underlie a general growth program but may instead play roles in synapse formation. 


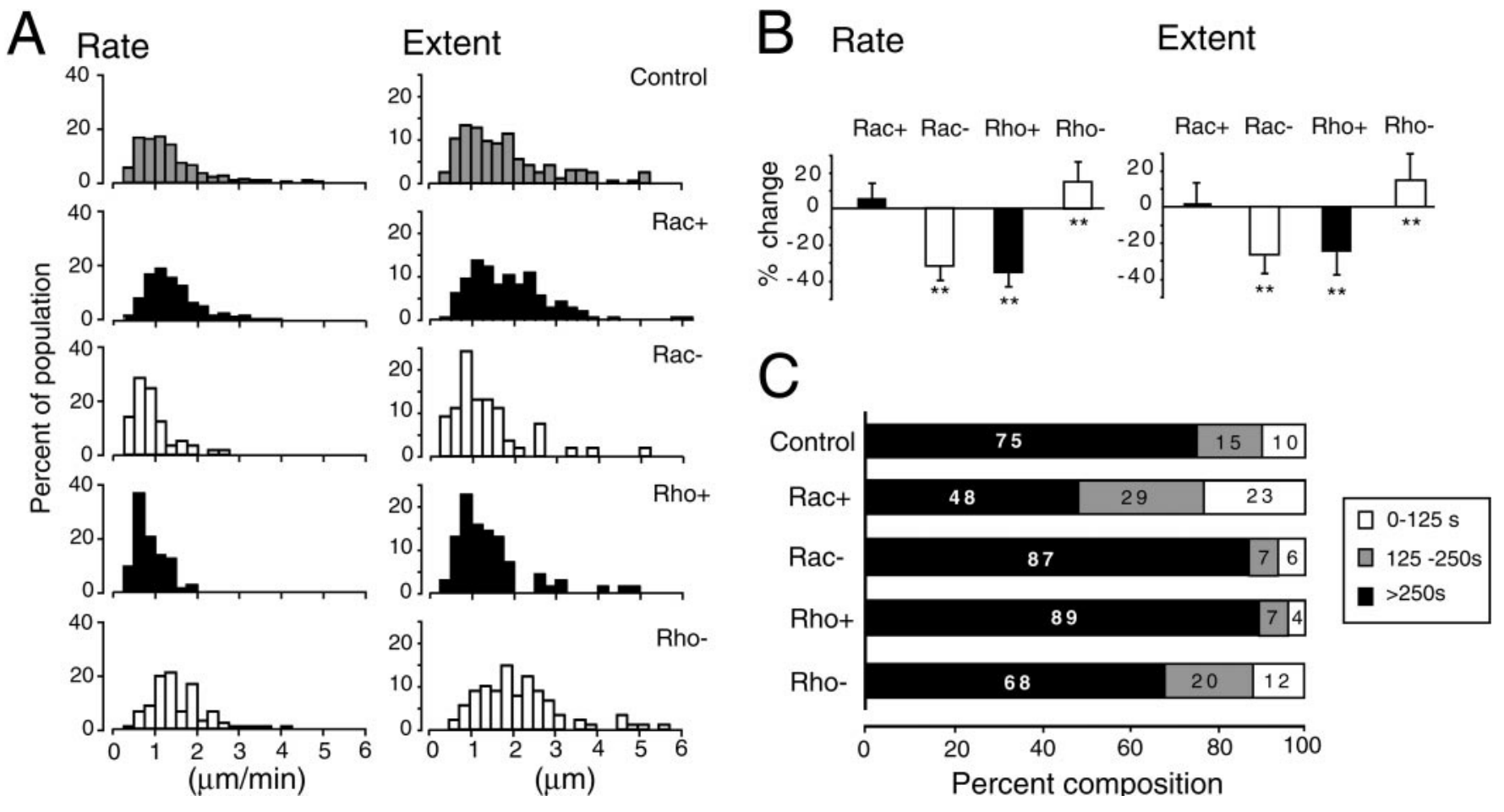

Figure 9. Rac and Rho regulate the rate, extent, and process turnover in dynamic processes in ganglion cells. $A$, Distributions of process rates $(l e f t)$ and extents (right) for cells with upregulated and downregulated levels of Rac or Rho activity. B, Percentage change in rates (left) and extents (right) for cells with upregulated and downregulated levels of Rac or Rho activity relative to that of control (Asterisks, $p<0.001$, Mann-Whitney $U$ test). $C$, Histograms showing the distributions of process lifetimes for cells with upregulated and downregulated levels of Rac or Rho activity. Numbers within the horizontal segments indicate the percent of the processes with the indicated lifetime range. Number of processes analyzed, Control $=165 ;$ Rac $+=147 ;$ Rac $-=$ 54 ; Rho $+=71 ;$ Rho $-=89$. Number of cells analyzed, Control $=14 ; \mathrm{Rac}+=9 ; \mathrm{Rac}-=5 ; \mathrm{Rho}+=7 ; \mathrm{Rho}-=7$.

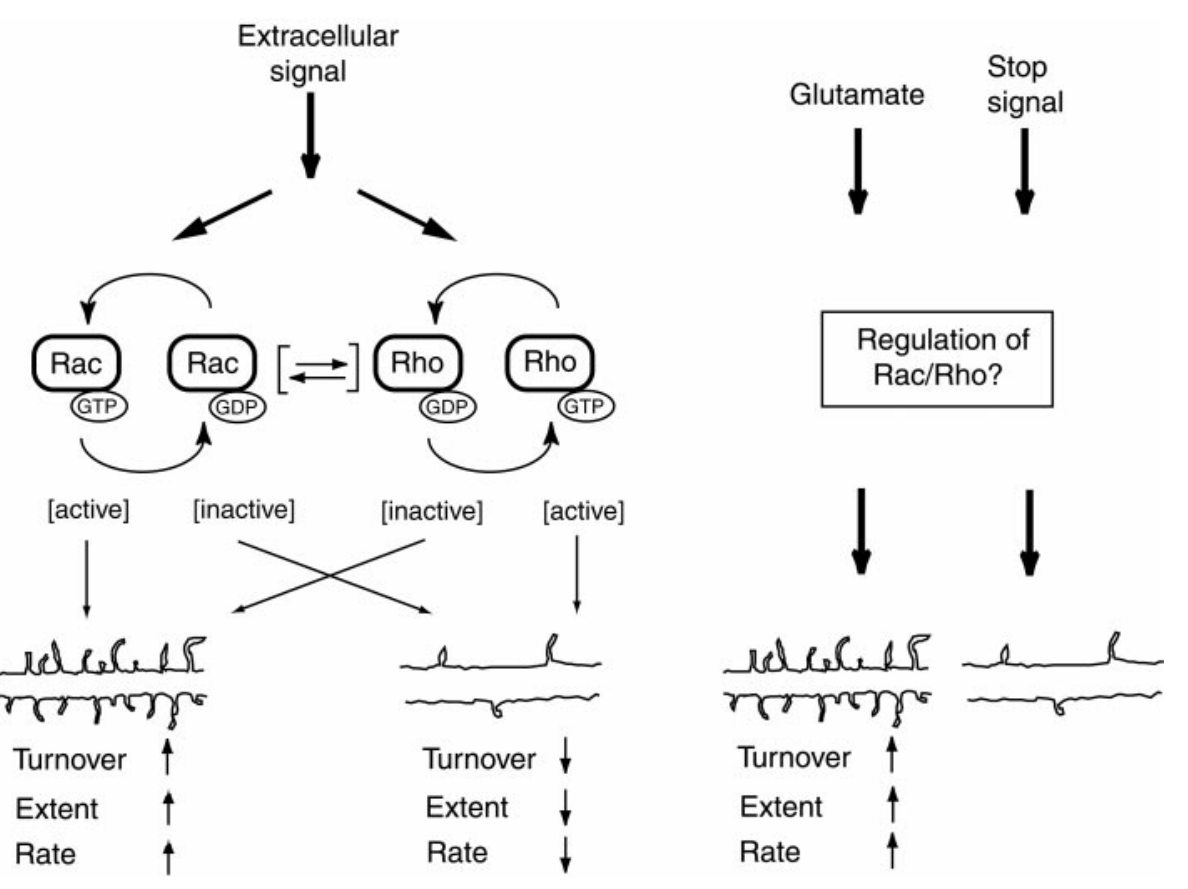

Figure 10. Model for the regulation of rapid dendritic modeling. Signals originating from presynaptic terminals and other extracellular sources are received at the cell membrane of dendritic processes. These signals are then transduced via intracellular pathways to affect the cycling of Rac and Rho between their GTP-bound (active) and GDP-bound (inactive) forms, thus controlling the intracellular levels of endogenous Rac and Rho activity. These levels of activity jointly control the organization and polymerization of the actin cytoskeleton that subsequently determine the rate at which dendritic processes move and are turned over. Rac and Rho exert opposite effects on dynamic remodeling, with Rac activity promoting greater motility and Rho suppressing it. The reciprocal control of dynamic dendritic behavior may be achieved by Rac and Rho exerting separate convergent effects on the actin cytoskeleton; it is also possible that they may exert antagonistic effects on each other directly. The potentiation of dendritic motility by glutamatergic transmission may be affected via these intracellular pathways, either via the upregulation of Rac activity, the downregulation of Rho activity, or both. Other extracellular cues, acting as stop signals, can also stabilize dendrites by regulating GTPase activity appropriately.

\section{Intercellular regulation of dendritic motility}

In the developing retina, bipolar cells drive synchronous activity in ganglion cells via glutamatergic neurotransmission (Wong et al., 2000). Because patterned activity is retained for $>24 \mathrm{hr}$ in explants, we were able to ask whether afferent signaling affects dendritic motility. We found that the blockade of endogenous ionotropic glutamatergic transmission significantly decreased dendritic motility. This result indicated that dendritic remodeling can be regulated by intercellular communication from presynaptic cells. Recent studies have demonstrated that tetanic stimulation of glutamatergic afferents to a local region of a dendritic arbor can elicit rapid increases in the length and number of terminal 
processes (Engert and Bonhoeffer, 1999; Maletic-Savatic et al., 1999) and the formation of multiple spine synapses (Toni et al., 1999). Our results extend those observations in an important way by demonstrating that neurotransmission in spontaneously active, developing circuits does indeed play a prominent endogenous role in regulating dendritic remodeling. In addition, we show here that glutamatergic signaling in developing circuits not only regulates how rapidly and extensively individual processes remodel but also maintains the overall size and complexity of the tree, by balancing the number of dendritic additions with an equal number of reductions. At the particular developmental stage examined, the effect is primarily mediated via ionotropic glutamatergic transmission, involving both NMDA and non-NMDA channels, as well as the influx of extracellular calcium.

Chronic in vivo application of D,L-2-amino-4-phosphonobutyric acid, which suppresses glutamatergic transmission from ON bipolar cells in the mature retina, reduces the specificity of stratification patterns of $\mathrm{ON}$ and $\mathrm{OFF}$ ganglion cell dendritic arbors (Bodnarenko and Chalupa, 1993; Bodnarenko et al., 1995; Bisti et al., 1998). Our time-lapse observations suggest that glutamatergic signaling might contribute to this stratification process of ganglion cells by promoting the growth or maintenance of dendrites only within the appropriate sublamina. But, our current observations do not distinguish between the effects of local versus global influences on dendritic dynamics and structure by neurotransmission. This would be an interesting avenue to pursue in future studies.

Dendritic remodeling is unperturbed by the blockade of sodium channel-mediated action potentials by TTX, corroborating previous in vivo studies on ganglion cells (Wong et al., 1991). This result also indicates that the regulation of process outgrowth in dendrites, unlike that in axons, occurs independently of sodium action potential activity (Sretavan et al., 1988; Dalva et al., 1994; O'Rourke et al., 1994). Our findings here contrast with those of Dunaevsky et al. (1999) that indicate that rapid changes in spines and filopodia in brain slices are not regulated by neuronal activity.

\section{Intracellular regulation of rapid dendritic motility}

In a wide variety of cell types, small GTPases in the Rho subfamily link extracellular signals to actin-dependent motility (for review, see Tapon and Hall, 1997; Van Aelst and D'SouzaSchorey, 1997; Hall, 1998). Three subfamilies within this family, Rho, Rac, and cdc42, have been well characterized. These factors are able to interact with each other but also can be activated by different extracellular cues acting on independent effectors to organize distinct cytoskeletal structures (Ridley and Hall, 1992; Ridley et al., 1992; Nobes and Hall, 1995). Recent studies have shown that members of this family regulate neuronal morphology, as well as the response of outgrowing neurites to intercellular signals (Luo et al., 1994, 1996; Jin and Strittmatter, 1997; Kozma et al., 1997; Lamoureux et al., 1997; Threadgill et al., 1997; Zipkin et al., 1997; Albertinazzi et al., 1998; Daniels et al., 1998; Kuhn et al., 1998, 1999).

In this study, we demonstrate a role for two GTPases, Rho and Rac, in the regulation of dendritic motility in developing neurons. Although levels of Rho and Rac activity influence the shape of dendritic trees (see Threadgill et al., 1997; Ruchhoeft et al., 1999), we have focused our analysis on their effects on the dynamism of terminal dendritic processes. Inhibition of Rac activity by the expression of dominant-negative Rac in ganglion cells decreased the process turnover rate and reduced both the rate and the extent of dendritic movements. Terminal dendritic processes persisted for a longer time than did those in control neurons, changing their lengths less markedly and at slower speeds. Conversely, upregulation of Rac function by expression of constitutively active Rac increased process turnover rate. $\mathrm{Rac}+$ did not, however, increase the rate and extent of process motility significantly, perhaps because basal motility is already close to its maximum level in the range modulated by Rac function.

In contrast to Rac, the downregulation of Rho activity by the expression of the dominant-negative mutant of Rho increased the rate and extent of process motility and also increased process turnover. Conversely, the upregulation of Rho activity by expression of a constitutively active mutant of Rho had the opposite effect on these motility parameters, indicating that, like Rac, Rho may also modulate the dynamics of remodeling by changing its level of activation. Thus, Rho activity acts to limit the speed and the range of remodeling events and promotes the stability of terminal processes.

Effects of Rho and Rac on dendritic motility are generally consistent with those on neurite outgrowth documented previously in dissociated cells. The inhibition of Rac function decreased process outgrowth elicited by cues such as nerve growth factor (Lamoureux et al., 1997; Daniels et al., 1998), $\beta 1$-integrin (Kuhn et al., 1998), and acetylcholine (Kozma et al., 1997). Conversely, inhibition of Rho activity prevented the retraction of neurites normally induced by exogenously applied lysophospholipid acid or thrombin (Jalink et al., 1994; Tigyi et al., 1996; Gebbink et al., 1997).

The reciprocal effects of Rac and Rho activity indicate a mutual antagonism in their regulation of dendritic motility. The situation is complex, in that Rac may activate Rho in some circumstances and antagonize it in others (for review, see Mackay and Hall, 1998). Antagonism has been noted previously in other neuronal culture systems in which structural changes induced by the activation of one GTPase can be antagonized or potentiated depending on whether the other GTPase is activated or inactivated, respectively (Kozma et al., 1997; Van Leeuwen et al., 1997; Hirose et al., 1998). This antagonism between Rac and Rho on dendritic remodeling posits a mechanism in which the dynamics of remodeling can be controlled precisely according to the balance of the two regulating GTPases (Fig. 8). Importantly, dendritic remodeling appears to be modulated by, rather than being absolutely dependent on, Rho and Rac activity because dendritic movements persist even when their activities are perturbed. These results are consistent with those of Lamoureux et al. (1997) and Zipkin et al. (1997).

\section{Roles of rapid dendritic motility}

Why do dendrites remodel rapidly? We initially considered the possibility that the rapid movements observed over tens of seconds contribute to the overall growth of the dendritic arbor, which also takes place during the embryonic period studied. Surprisingly, however, this seems not to be the case; as noted above, the rapid movements are balanced across the arbor and therefore contribute little to net growth. Instead, several observations support an alternative possibility, that the rapid movements promote synaptogenesis. First, the movements are primarily restricted to tertiary branches, which are the portions of the arbor on which most synapses form. Differentiated synapses first appear on the chick retinal ganglion cell dendrites at E12-E13, at the time that we examine their motility (Hughes and LaVelle, 
1974; Hering and Kroger, 1996). In neonatal cat retinal ganglion cells, filopodia have been observed by electron microscopy to be associated with presynaptic specializations, even though the majority of differentiated synapses are on dendritic shafts (Wong et al., 1992). Similarly, dendritic filopodia in the developing hippocampus have also been associated with differentiated synapses (Fiala et al., 1998). Second, motility is high at E12-E13, when synaptogenesis is at its peak, and then declines by E15-E16, when synaptogenesis is more advanced. In this respect, our results are consistent with those of Dailey and Smith (1996), Ziv and Smith (1996), and Fischer et al. (1998), all of which report lower levels of endogenous dendritic motility in more mature systems. Third, the balanced movements allow dendritic branches to over time sample a severalfold larger volume than that physically occupied at any single point in time. As Ziv and Smith (1996) noted, this expanded volume increases the probability that an afferent would contact its appropriate postsynaptic partner. Fourth, intracellular modulators of motility include the Rho family of GTPases, which are well established as intracellular regulators of axonal motility and dendritic morphology and have been implicated in synaptogenesis in invertebrates (Sone et al., 1997). Finally, dendritic motility is modulated by excitatory neurotransmission. Throughout the nervous system, patterns of synaptic connectivity are modulated by synaptic activity (Goodman and Shatz, 1993; Lichtman et al., 1998).

How might synaptic enhancement of motility promote synaptogenesis? Motor axons can release their neurotransmitter (acetylcholine) even before forming close contacts with myotubes (Hume et al., 1983; Young and Poo, 1983). If the same is true for excitatory inputs to retinal ganglion cells, released neurotransmitter would stimulate dendritic exploration as afferents approach, increasing the probability of close contact. On the other hand, unchecked enhancement of motility by glutamate receptor activation might be counterproductive, because activity presumably increases as synaptogenesis proceeds yet the desired outcome is a stable synapse. However, numerous extracellular factors are known that can arrest axonal advance by causing growth cones to collapse, and it is reasonable to imagine that some of them might also arrest dendritic motility. For example, molecular cues such as ephrins or semaphorins might act as stop signals, arresting dendritic motility after contact is established and thereby overcoming the motility-promoting effects of activity.

In this regard, the reciprocal effects of Rho and Rac on dendritic motility may be especially pertinent. The similar effects of glutamate, Rac activation, and Rho inhibition on dendritic dynamics (Figs. 8, 10) invite the speculation that synaptic activity promotes motility by activating Rac and/or inhibiting Rho. Conversely, effects of at least one collapsing factor, lysophosphatidic acid, appear to be mediated by activation of Rho (Jalink et al., 1994; Tigyi et al., 1996; Gebbink et al., 1997; Kozma et al., 1997). We suggest that the Rho family of GTPases provides a means by which the dendrite integrates multiple extracellular factors to optimize the extent, and perhaps even the direction, of its movement. In this way, afferents could use a combination of diff usible and contact-mediated cues first to maximize the probability of synaptic contact and subsequently to transform that contact into a functional synapse.

\section{REFERENCES}

Albertinazzi C, Gilardelli D, Paris S, Longhi R, de Curtis I (1998) Overexpression of a neural-specific rho family GTPase, cRac1B, selectively induces enhanced neuritogenesis and neurite branching in primary neurons. J Cell Biol 142:815-825.
Berry M, Bradley PM (1976) The application of network analysis to the study of branching patterns of large dendritic fields. Brain Res 109:111-132.

Bisti S, Gargini C, Chalupa LM (1998) Blockade of glutamate-mediated activity in the developing retina perturbs the functional segregation of ON and OFF pathways. J Neurosci 18:5019-5025.

Bodnarenko SR, Chalupa LM (1993) Stratification of ON and OFF ganglion cell dendrites depends on glutamate-mediated afferent activity in the developing retina. Nature 364:144-146.

Bodnarenko SR, Jeyarasasingam G, Chalupa LM (1995) Development and regulation of dendritic stratification in retinal ganglion cells by glutamate-mediated afferent activity. J Neurosci 15:7037-7045.

Cooper JA (1987) Effects of cytochalasin and phalloidin on actin. J Cell Biol 105:1473-1478.

Cooper MW, Smith SJ (1992) A real-time analysis of growth cone-target cell interactions during the formation of stable contacts between hippocampal neurons in culture. J Neurobiol 23:814-828.

Dailey ME, Smith SJ (1996) The dynamics of dendritic structure in developing hippocampal slices. J Neurosci 16:2983-2994.

Dalva MB, Ghosh A, Shatz CJ (1994) Independent control of dendritic and axonal form in the developing lateral geniculate nucleus. J Neurosci 14:3588-3602.

Daniels RH, Hall PS, Bokoch GM (1998) Membrane targeting of p21activated kinase 1 (PAK1) induces neurite outgrowth from PC12 cells. EMBO J 17:754-764.

Diekmann D, Brill S, Garrett MD, Totty N, Hsuan J, Monfries C, Hall C, Lim L, Hall A (1991) Bcr encodes a GTPase-activating protein for p21rac. Nature 351:400-402.

Dunaevsky A, Tashiro A, Majewska A, Mason A, Yuste R (1999) Developmental regulation of spine motility in the mammalian central nervous system. Proc Natl Acad Sci USA 96:13438-13443.

Engert F, Bonhoeffer T (1999) Dendritic spine changes associated with hippocampal long-term synaptic plasticity. Nature 399:66-70.

Fiala JC, Feinberg M, Popov V, Harris KM (1998) Synaptogenesis via dendritic filopodia in developing hippocampal area CA1. J Neurosci 18:8900-8911.

Fischer M, Kaech S, Knutti D, Matus A (1998) Rapid actin-based plasticity in dendritic spines. Neuron 20:847-854.

Gebbink MF, Kranenburg O, Poland M, van Horck FP, Houssa B, Moolenaar WH (1997) Identification of a novel, putative Rho-specific GDP/GTP exchange factor and a RhoA-binding protein: control of neuronal morphology. J Cell Biol 137:1603-1613.

Goodman CS, Shatz CJ (1993) Developmental mechanisms that generate precise patterns of neuronal connectivity. Cell [Suppl] 72:77-98.

Hall A (1998) Rho GTPases and the actin cytoskeleton. Science 279:509-514.

Hering H, Kröger S (1996) Formation of synaptic specializations in the inner plexiform layer of the developing chick retina. J Comp Neurol 375:393-405.

Hirose M, Ishizaki T, Watanabe N, Uehata M, Kranenburg O, Moolenaar WH, Matsumura F, Maekawa M, Bito H, Narumiya S (1998) Molecular dissection of the Rho-associated protein kinase (p160ROCK)regulated neurite remodeling in neuroblastoma N1E-115 cells. J Cell Biol 141:1625-1636.

Hughes WF, LaVelle A (1974) On the synaptogenic sequence in the chick retina. Anat Rec 179:297-301.

Hume RI, Role LW, Fischbach GD (1983) Acetylcholine release from growth cones detected with patches of acetylcholine receptor-rich membranes. Nature 305:632-634.

Jalink K, van Corven EJ, Hengeveld T, Morii N, Narumiya S, Moolenaar WH (1994) Inhibition of lysophosphatidate- and thrombin-induced neurite retraction and neuronal cell rounding by ADP ribosylation of the small GTP-binding protein Rho. J Cell Biol 126:801-810.

Jin Z, Strittmatter SM (1997) Rac1 mediates collapsin-1-induced growth cone collapse. J Neurosci 17:6256-6263.

Jontes JD, Buchanan J, Smith SJ (2000) Growth cone and dendrite dynamics in zebrafish embryos: early events in synaptogenesis imaged in vivo. Nat Neurosci 3:231-237.

Kozma R, Sarner S, Ahmed S, Lim L (1997) Rho family GTPases and neuronal growth cone remodelling: relationship between increased complexity induced by $\mathrm{Cdc} 42 \mathrm{Hs}$, Rac1, and acetylcholine and collapse induced by RhoA and lysophosphatidic acid. Mol Cell Biol 17:1201-1211.

Kuhn TB, Brown MD, Bamburg JR (1998) Rac1-dependent actin filament organization in growth cones is necessary for beta1-integrin- 
mediated advance but not for growth on poly-D-lysine. J Neurobiol 37:524-540.

Kuhn TB, Brown MD, Wilcox CL, Raper JA, Bamburg JR (1999) Myelin and collapsin-1 induce motor neuron growth cone collapse through different pathways: inhibition of collapse by opposing mutants of rac1. J Neurosci 19:1965-1975.

Lamoureux P, Altun-Gultekin ZF, Lin C, Wagner JA, Heidemann SR (1997) Rac is required for growth cone function but not neurite assembly. J Cell Sci 110:635-641.

Lichtman JW, Burden SJ, Culican SM, Wong ROL (1998) Synase formation and elimination. In: Fundamental neuroscience (Zigmond MJ, Bloom FE, Landis SC, Roberts JL, Squire LR, eds), pp 547-580. San Diego: Academic.

Lo DC, McAllister AK, Katz LC (1994) Neuronal transfection in brain slices using particle-mediated gene transfer. Neuron 13:1263-1268.

Luo L, Liao YJ, Jan LY, Jan YN (1994) Distinct morphogenetic functions of similar small GTPases: Drosophila Drac1 is involved in axonal outgrowth and myoblast fusion. Genes Dev 8:1787-1802.

Luo L, Jan L, Jan YN (1996) Small GTPases in axon outgrowth. Perspect Dev Neurobiol 4:199-204.

Mackay DJG, Hall A (1998) Rho GTPases. J Biol Chem 273:20685-20688.

Maletic-Savatic M, Malinow R, Svoboda K (1999) Rapid dendritic morphogenesis in CA1 hippocampal dendrites induced by synaptic activity. Science 283:1923-1927.

Malosio ML, Gilardelli D, Paris S, Albertinazzi C, de Curtis I (1997) Differential expression of distinct members of Rho family GTP-binding proteins during neuronal development: identification of Rac1B, a new neural-specific member of the family. J Neurosci 17:6717-6728.

Markham JA, Fifkova E (1986) Actin filament organization within dendrites and dendritic spines during development. Brain Res 392:263-269.

Matus A, Ackermann M, Pehling G, Byers HR, Fujiwara K (1982) High actin concentrations in brain dendritic spines and postsynaptic densities. Proc Natl Acad Sci USA 79:7590-7594.

Mueller BK (1999) Growth cone guidance: first steps towards a deeper understanding. Annu Rev Neurosci 22:351-388.

Nobes CD, Hall A (1995) Rho, rac, and cdc42 GTPases regulate the assembly of multimolecular focal complexes associated with actin stress fibers, lamellipodia, and filopodia. Cell 81:53-62.

O'Rourke NA, Cline HT, Fraser SE (1994) Rapid remodeling of retinal arbors in the tectum with and without blockade of synaptic transmission. Neuron 12:921-934.

Rajan I, Cline HT (1998) Glutamate receptor activity is required for normal development of tectal cell dendrites in vivo. J Neurosci 18:7836-7846.

Rajan I, Witte S, Cline HT (1999) NMDA receptor activity stabilizes presynaptic retinotectal axons and postsynaptic optic tectal cell dendrites in vivo. J Neurobiol 38:357-368.

Ridley AJ, Hall A (1992) The small GTP-binding protein rho regulates the assembly of focal adhesions and actin stress fibers in response to growth factors. Cell 70:389-399.

Ridley AJ, Paterson HF, Johnston CL, Diekmann D, Hall A (1992) The small GTP-binding protein rac regulates growth factor-induced membrane ruffling. Cell 70:401-410.

Rodieck RW (1998) The first steps in seeing. Sunderland, MA: Sinauer.

Ruchhoeft ML, Ohnuma S, McNeill L, Holt CE, Harris WA (1999) The neuronal architecture of Xenopus retinal ganglion cells is sculpted by rho-family GTPases in vivo. J Neurosci 19:8454-8463.

SAS (1996) SAS/STAT software changes and enhancements, p 1104. Cary, NC: SAS.

Sernagor E, Eglen S, O'Donovan MJ (2000) Differential effects of acetylcholine and glutamate blockade on the spatiotemporal dynamics of retinal waves. J Neurosci 20:1-6.
Sone M, Hoshino M, Suzuki E, Kuroda S, Kaibuch K, Nakagoshi H, Saigo K, Nabeshima Y, Hama C (1997) Still life, a protein in synaptic terminals of Drosophila homologous to GDP-GTP exchangers. Science 275:543-547.

Spector I, Shochet NR, Blasberger D, Kashman Y (1989) Latrunculinsnovel marine macrolides that disrupt microfilament organization and affect cell growth. I. Comparison with cytochalasin D. Cell Motil Cytoskeleton 13:127-144.

Sretavan DW, Shatz CJ, Stryker MP (1988) Modification of retinal ganglion cell axon morphology by prenatal infusion of tetrodotoxin. Nature 336:468-471.

Tapon N, Hall A (1997) Rho, Rac and Cdc42 GTPases regulate the organization of the actin cytoskeleton. Curr Opin Cell Biol 9:86-92.

Thanos S, Vanselow J, Mey J (1992) Ganglion cells in the juvenile chick retina and their ability to regenerate axons in vitro. Exp Eye Res 54:377-391.

Threadgill R, Bobb K, Ghosh A (1997) Regulation of dendritic growth and remodeling by Rho, Rac, and Cdc42. Neuron 19:625-634.

Tigyi G, Fischer DJ, Sebok A, Yang C, Dyer DL, Miledi R (1996) Lysophosphatidic acid-induced neurite retraction in PC12 cells: control by phosphoinositide-Ca2+ signaling and Rho. $\mathrm{J}$ Neurochem 66:537-548.

Toni N, Buchs PA, Nikonenko I, Bron CR, Muller D (1999) LTP promotes formation of multiple spine synapses between a single axon terminal and a dendrite. Nature 402:421-425.

Van Aelst L, D'Souza-Schorey C (1997) Rho GTPases and signaling networks. Genes Dev 11:2295-2322.

Van Leeuwen FN, Kain HET, van der Kammen RA, Michiels F, Kranenburg OW, Collard JG (1997) The guanine nucleotide exchange factor Tiam1 affects neuronal morphology; opposing roles for the small GTPases Rac and Rho. J Cell Biol 139:797-807.

Vaughn JE (1989) Fine structure of synaptogenesis in the vertebrate central nervous system. Synapse 3:255-285.

Vaughn JE, Henrikson CK, Grieshaber JA (1974) A quantitative study of synapses on motor neuron dendritic growth cones in developing mouse spinal cord. J Cell Biol 60:664-672.

Wong ROL (1999) Retinal waves and visual system development. Annu Rev Neurosci 22:29-47.

Wong ROL, Hermann K, Shatz CJ (1991) Remodeling of retinal ganglion cell dendrites in the absence of action potential activity. J Neurobiol 22:685-697.

Wong ROL, Yamawaki RM, Shatz CJ (1992) Synaptic contacts and the transient dendritic spines of developing retinal ganglion cells. Eur J Neurosci 4:1387-1397.

Wong ROL, Chernjavsky A, Smith SJ, Shatz CJ (1995) Early functional neural networks in the developing retina. Nature 374:716-718.

Wong WT, Sanes JR, Wong ROL (1998) Developmentally regulated spontaneous activity in the embryonic chick retina. J Neurosci 18:8839-8852.

Wong WT, Myhr KL, Miller ED, Wong ROL (2000) Developmental changes in the neurotransmitter regulation of correlated spontaneous retinal activity. J Neurosci 20:306-314.

Young SH, Poo MM (1983) Spontaneous release of transmitter from growth cones of embryonic neurones. Nature 305:634-637.

Yuste R, Denk W (1995) Dendritic spines as basic functional units of neuronal integration. Nature 375:682-684.

Yuste R, Tank DW (1996) Dendritic integration in mammalian neurons, a century after Cajal. Neuron 16:706-716.

Zipkin ID, Kindt RM, Kenyon CJ (1997) Role of a new Rho family member in cell migration and axon guidance in $C$. elegans. Cell 90:883-894.

Ziv NE, Smith SJ (1996) Evidence for a role of dendritic filopodia in synaptogenesis and spine formation. Neuron 17:91-102. 